\title{
A MULTI-PERIOD RISK SHARING SUPPLY CHAIN CONTRACT UNDER CONSIDERATION OF PRICE AND DEMAND UNCERTAINTIES
}

by

\author{
Isil Tari \\ MASc (Industrial Engineering) \\ Tobb University of Economics and Technology, \\ Ankara, Turkey, 2013 \\ BSc (Industrial Engineering) \\ Atilim University, \\ Ankara, Turkey, 2010 \\ An MRP \\ presented to Ryerson University \\ in partial fulfillment of the \\ requirements for the degree of \\ Master of Engineering \\ in the Program of \\ Mechanical and Industrial Engineering
}

Toronto, Ontario, Canada, 2016

(c) Isil Tari 2016 


\section{AUTHOR'S DECLARATION}

I hereby declare that I am the sole author of this MRP. This is a true copy of the MRP, including any required final revisions.

I authorize Ryerson University to lend this MRP to other institutions or individuals for the purpose of scholarly research.

I further authorize Ryerson University to reproduce this MRP by photocopying or by other means, in total or in part, at the request of other institutions or individuals for the purpose of scholarly research.

I understand that my MRP may be made electronically available to the public. 


\title{
A MULTI-PERIOD RISK SHARING SUPPLY \\ CHAIN CONTRACT UNDER CONSIDERATION \\ OF PRICE AND DEMAND UNCERTAINTIES
}

\author{
Isil Tari \\ Master of Engineering, Mechanical and Industrial Engineering, \\ 2016 \\ Ryerson University
}

\begin{abstract}
Exchange rate is extremely volatile and displays a Markovian regime switching property. This report proposes a multi-period procurement problem with a flexible quantity risk-sharing supply contract that may provide a prevention against exchange rate (FX) fluctuations for international traders. The buyer assumed to be encountered with a random price modelled by a regime-switching geometric Brownian motion and also random demand. The proposed risk sharing supply contract model helps to compensate supplier for the depreciating market price and also helps buyer when purchase price increases. According to the author's knowledge, none of the studies in the literature considers a risk-sharing supply contract with random demand and random price while modelling the exchange rates by regime switching approach. Multi-period lattice model is developed for valuation of risk-sharing supply contract. The problem is solved with using dynamic programming approach. A numerical example and sensitivity analyses are presented to illustrate the proposed model.
\end{abstract}




\section{Acknowledgements}

I am deeply indebted to my project supervisor, Dr. Mohamed Wahab Mohamed Ismail, for his valued and generous guidance and encouragement. His patience has played a fundamental role for this study. I am very thankful for giving me this opportunity to work under his supervision.

At the same time I appreciate the generous support given to me by my husband Serdar Tari, my mother Ulku Basmaci and my father Murat Basmaci. 


\section{Table of Contents}

Author's Declaration $\quad$ ii

$\begin{array}{ll}\text { Abstract } & \text { iii }\end{array}$

Acknowledgement $\quad$ iv

Table of Contents $\quad$ v

List of Tables $\quad$ vii

List of Figures $\quad$ viii

List of Abbreviations $\quad$ xi

1 Introduction $\quad 1$

2 Supply Chain Contracts and Regime Switching Processes 3

2.1 An Overview to the Supply Network Structure . . . . . . . . . . . . . 3

2.2 Supply Chain Contracts . . . . . . . . . . . . . . 5

2.2.1 Categorization of Supply Chain Contracts . . . . . . . . 6

2.3 Regime Switching Process . . . . . . . . . . . . . . . . . 10

2.3.1 Properties of Markov Switching Model . . . . . . . . . . . . . . 12

2.3.2 Exchange Rate Regime Switching Process . . . . . . . . . . . 14 
3.1 Valuation Methods of Financial and

Real Options ............................. 16

3.2 Supply Chain Contracts . . . . . . . . . . . . . . . . . 18

3.3 Regime Switching Studies for Exchange Rates . . . . . . . . . . . . . . . 23

4 The Model $\quad 26$

4.1 Problem Definition . . . . . . . . . . . . . . . . . . 26

4.2 Regime-Switching Exchange Rate Model . . . . . . . . . . . . . . . . . . 28

4.3 Lattice Approach . . . . . . . . . . . . . . . . . . . . . . . . . . . 29

4.4 Valuation of Contracts . . . . . . . . . . . . . . . . . 32

5 An Example and Sensitivity Analyses 36

5.1 Numerical Example . . . . . . . . . . . . . . . . . . 36

5.2 Sensitivity Analyses . . . . . . . . . . . . . . . . . . . 41

5.2.1 Changes in the gross margin . . . . . . . . . . . . . . . 41

5.2.2 Changes in the mean of demand . . . . . . . . . . . . . . 42

5.2.3 Changes in the standard deviation of demand . . . . . . . . . . 42

5.2.4 Changes in the holding cost . . . . . . . . . . . . . 44

5.2.5 Changes in the risk-sharing ratio . . . . . . . . . . . . 45

5.2.6 Changes in the lower price . . . . . . . . . . . . . 46

5.2.7 Changes in the upper price . . . . . . . . . . . . 47

5.2.8 Changes in the standard deviations of the exchange rate for regime

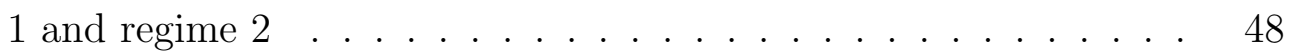

5.2.9 Changes of the exchange rate standard deviation for the single

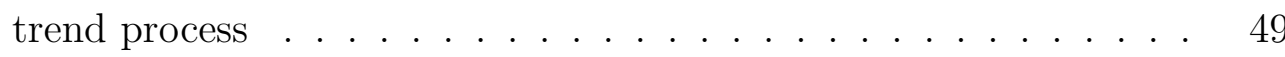

6 Conclusion $\quad 51$ 
Bibliography 


\section{List of Tables}

5.1 Estimated regime parameters for exchange rate in CAD per 100 units of

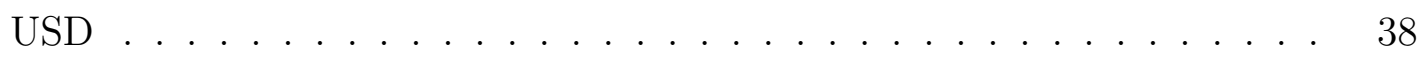

5.2 Estimated parameters for exchange rate in CAD per 100 units of USD . . 38 


\section{List of Figures}

2.1 A time series with a regime switch (Marin et al. 2014) . . . . . . . . . 11

2.2 Memory card supply history (Bollen 1999) . . . . . . . . . . . . . . 12

2.3 Markov regime-switching process for two state (Bergman and Hansson 2005) 14

4.1 Multinomial lattice-one step . . . . . . . . . . . . . . . . . 31

4.2 Two-regime process for an exchange rate . . . . . . . . . . . . . 33

5.1 Daily exchange rate in CAD per USD from August 5, 2010 and October

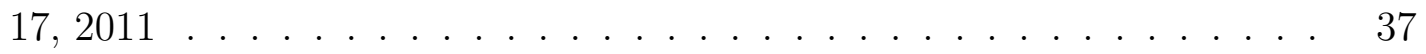

5.2 Two regimes with smoothed probability for the daily exchange rate in CAD per 100 units of USD . . . . . . . . . . . . . . 37

5.3 Unit purchase prices . . . . . . . . . . . . . . . . . 40

5.4 Optimal net present values . . . . . . . . . . . . . . . . . 40

5.5 Changes in the gross margin . . . . . . . . . . . . . . . . 41

5.6 Changes in mean of demand . . . . . . . . . . . . . . . . . . . . 42

5.7 Changes in the standard deviation of demand . . . . . . . . . . . 43

5.8 Changes in the holding cost . . . . . . . . . . . . . . . . 44

5.9 Changes in the risk-sharing ratio . . . . . . . . . . . . . 45

5.10 Changes in the lower price . . . . . . . . . . . . . . 46

5.11 Changes in the upper price . . . . . . . . . . . . . . . 47

5.12 Changes of the exchange rate standard deviation for regime $1 \ldots$. . . 48 
5.13 Changes of the exchange rate standard deviation for regime $2 \ldots \ldots$

5.14 Changes of the exchange rate standard deviation for a single regime model 50 


\section{List of Abbreviations}

$\mu \quad$ Brownian motion drift parameter (mean demand)

$\sigma^{2} \quad$ Variance of demand

D Demand per period

$h \quad$ Unit inventory holding cost per period

c Unit purchase price of a product

$\alpha \quad$ Gross margin

$S \quad$ Maximum inventory level (order-up-to level)

$r \quad$ Constant interest rate per year

$x \quad$ Amount of product that ordered from a buyer

y Optimal order-up-to level

$\mu_{i} \quad$ Exchange rate Brownian motion drift parameter in regime $i$ (mean exchange rate)

$\sigma_{i}^{2} \quad$ Variance of the exchange rate in regime $i$

$\lambda \quad$ Risk sharing ratio

$\bar{P} \quad$ Upper unit price

$\underline{P} \quad$ Lower unit price

$\hat{\phi}_{i} \quad$ Step size of regime $i$

$\Delta t \quad$ Time difference between two discrete sections of the lattice

$l \quad$ The level of exchange rate (branch position)

$z(x, i, c, t) \quad$ Optimal net present value given that the inventory level at

period $t$ when ordering $x$, and that the purchase price is

$c$ when regime is $i$

$G(y, i, c, t)$ Contract value known that optimal order-up-to level $y$ at time $t$ when unit purchase price is $c$ in regime $i$ 


\section{Chapter 1}

\section{Introduction}

Supply chain is a system of all resources, activities and organizations participated in the procurement, designing, distributing, storing and sale of a good from delivery of raw materials through to the end users. Coordinating the information, product, and cash flow within and among organizations is described as supply chain management (Albeniz and Simchi-Levi 2015). Some of the decision requirements of managing the supply chain are design of a product, the choice of which suppliers to use, the selection of inputs at each stage, transportation of inputs, suitable inventory storing, and lastly the end price of the product. No single business can control all these activities and objectives along the supply chain. Therefore, a systematic coordination is needed for optimal decisions to make while reaching the ultimate goals.

A contract method is a fruitful way for coordinating the supply network. That is, it is a arrangement among different organizations in supply chain networks relating to the various variables for instance purchase amount, price, delivery, and so on. Deciding on a proper purchasing strategy in terms of cost is a primary issue for the supply network. In

this study, a model is developed for a dynamic price market environment while evaluating the quantity flexible risk-sharing supply contract with random demand and random price. The aim of the problem is to find out an appropriate purchasing quantity and time when 
exchange rate is volatile for the purchased products. It is examined a case that a Canadian buyer signs an agreement to an American supplier for the price of a flexible quantity of product to fulfil their customer's demand over a multiple period. The problem is modelled as a multi-period procurement problem and solved by the dynamic programming method. A realistic implementation of the problem for a Canadian company is presented. And also, some empirical analyses for the effect of changes in the problem parameters on the results are conducted.

According to the author, none of the studies in the literature considers a risk sharing and flexible quantity agreement under random price while modelling the exchange rates by regime switching approach.

This study contains six Chapters. In Chapter 2, some basic concept of supply contracts and regime switching processes are introduced. For Chapter 3, a literature review about financial and real options valuation methods, supply contracts and regime switching studies for exchange rates are presented. In Chapter 4, the problem definition, regime switching exchange rate model, lattice approach and multi-period dynamic programming mathematical model are presented. In Chapter 5, a numerical example is illustrated by using the proposed model in Chapter 4. Lastly, the project report concludes with some final remarks and future research directions presented in Chapter 6. 


\section{Chapter 2}

\section{Supply Chain Contracts and Regime Switching Processes}

This section gives a brief overview about the supply network and its contracts. Furthermore, an information about regime switching processes for exchange rates are explained.

\subsection{An Overview to the Supply Network Structure}

Supply chain is a sophisticated network that comprises series of activities such as procurement of raw materials, value addition to these materials through transformation into semi-finished and finished goods, and lastly distribution to final buyers (Bassok and Anupindi 1997). Management of the supply network interested in controlling information, materials, and cash flows formed with suppliers, producers, distributors, retailers, and buyers. The primary aims of the supply network management is to be productive and profitable by minimizing total expenditures across the entire system.

Every organization has different conflicting objectives in the network such as suppliers want producers to purchase large and stable quantities with steady delivery times. Supplier's this desire conversely clashes with distribution facilities and warehouses to pull down inventory on hand. Producers must be agile to their customers' desires and 
fluctuate demands. Hence, they prefer more flexible procurements. Therefore, supplier's goal is in conflict with the producer's wish for flexibility. As manufacturing plans are applied mostly with no certain knowledge about demands, adjusting supply amount when demand data come is important in order to balance the supply and demand. So, being flexible is the key point for demand uncertainties in the supply chain management (Li et al. 2009).

Supply chain has a dynamic network structure changes regularly during the time. For instance, amount of requirements and supplier allocation capacities may alter within the time. Hence, this situation leads to leads to a problem in providing customer expectations and minimizing overall expenditures. Besides, price and demand variables vary during the time as the effect of promotions, seasonal demand alterations, market price tactics and so on (Feng et al. 2013).

Among the most fundamental problem in managing the supply network is uncertainty because of the fact that it costs additional money. There are different reasons that lead to uncertainty such as seasonal fluctuations, demand variabilities, logistics, and quality deficiencies. As a result, a company needs to hold surplus inventory on hand for both meeting the customer demands preventing a lost sale risk and carry on daily operations (Fotopoulos et al. 2008). When companies increase their inventory, their ability to meet higher service levels increases. So, holding excess inventory is a major component of risk hedging, because firms nowadays could not manage being stock-out as a consequence of any kinds of supply chain breakdown. If they cannot meet their customers expectations, customers will go to different suppliers/sources. Therefore, the management of the uncertainties has a huge priority to achieve an effective supply chain management (Gurnani and Tang 1999). 


\subsection{Supply Chain Contracts}

In the previous section, it is mentioned that organizations in supply chain network have different contradictory objectives. However, biased optimal decisions can cause operational inefficiencies ( $\mathrm{Hu}$ et al. 2013b). Generally, there are two approaches in decision making structure of supply chain. First one is centralized policy in which minimizes the total cost of the system by managing a central authority who is responsible for decision making. Second one is the decentralized policy in which the vendor and producer behave like two independent agent want to maximize their benefit without taking into account overall network's profit. The centralized network's profit is higher than the decentralized one. The supplier must propose suitable contract to the manufacturer so that coordination is achieved (Munson et al. 2012).

A contract method is a good way to obtain a regulation inside the supply networks that provides sharing risks and benefits by changing the parameters between the organizations. Another words, supply chain contract could be described as an agreement among different organizations in the network relating to the different variables such as pricing, order quantity, delivery and so on. An important goal of the contracts is to coordinate the supply network which results in minimizing the overall supply network's cost. The other benefit of the supply contract is ensuring to meet customers' uncertain and changing demands. Another motivation is sharing the system's risks and costs emerging due to the uncertainty in the network. It also provides opportunity for suppliers and buyers to build enough capacity. The other cause is establishing long-term connections with attending a continuous business partnership, supplier and purchaser decrease their overall expenses as pricy researches as well as negotiations are reduced. For example, according to executives at AMD's Memory Group, supply contracts secure millions of dollars that funding in an advanced manufacturing centres which is practically be operated (Hochbaum and Wagner 2015). 


\subsubsection{Categorization of Supply Chain Contracts}

There are numerous supply network contract types within literature in order to improve the coordination. These are buy-back (return), revenue-sharing, quantity discount, risksharing, wholesale price, quantity flexible, options, commitment contracts and so on ( $\mathrm{Li}$ et al. 2009).

The returns policy or buy-back contract and revenue sharing contracts are two of the most commonly studied coordination contracts when the product has a fixed price. The buy-back (return) policy is generally exercised for merchandises such as computers and cell phones which have short product life-cycles. The supplier deals to buy remained unsold inventory at a lower value than the first price. Besides, revenue-sharing agreement coordinates the network when contract variable are chosen appropriately. For the a revenue-sharing policy, the buyer gives to a seller a pay for each unit purchased, and in addition to proportion of the revenue that the buyer gain. With commitment policy, the buyer is obligated to purchase a specified amount during the time horizon. With option policy, the buyer possess an option to purchase up to a specified amount during the time horizon (Sethi et al. 2004). Option contract denotes a contract that combines time flexibility with no minimum purchase requirement. A Blomberg Businessweek article reported that Intel has saved $\$ 125$ million during 2008-2012 due to option contract (Hochbaum and Wagner 2015). And commitment contract denotes a contract that combines time flexibility with an obligation to purchase a specified amount during the time horizon.

In addition to optimizing the supply chain coordination, some studies propose models for comprehensive contract parameters such as time horizon length, pricing, quantity and time flexibility, quality and information sharing under specific assumptions such as demand is deterministic or stochastic and purchasing price is certain or uncertain.

In recent days, people are living in an economically global world with a high product variety. Technological improvements are growing rapidly day by day. Thus, demand and 
price turn into extremely uncertain for so many industries. Therefore, enhancing the power of estimating price and demand is a great challenge for plenty of firms especially in context of new products with volatile demand (Hu et al. 2013a). For instance, after Apple put its i-Pod Touch on the market, a shortage of screens for the product was occurred within a short time in Autumn 2007 (Guglielmo and Hesseldahl 1 19). However, the producer didn't estimate this popularity for the product and didn't contract for an enough amount of touch-screens. Besides, there were no other suppliers that had production capacity and could provide the additional units. Therefore, Apple experienced an important backlogs such as loss of goodwill and loss of sales. In February 2010, Apple contracted for all the available suppliers for a specific inch screen for both itself and for creating a scarcity of such screens in the marketplace for its competitors (Guglielmo and Hesseldahl 1 19). Sales prices changing for a several reasons such as supply and demand uncertainty, foreign exchange rate trends, political and macroeconomic factors, technological improvements and so on. As a result the buyer pays under or above than the original price (Yuan 2011).

One of the fundamental aim for the agreements is to ensure the availability of right quantity and quality of goods within the right time and at the lowest possible payment. On the other hand, buyers like the flexibility to place orders and then change these orders as they have more information about future demands. In many supply contract cases, the right balance between stability and flexibility to allocate the risk between buyers and sellers is playing an important role (Fotopoulos et al. 2008). Due to the mentioned price changing environments, supply contracts comprise time flexibility that is letting the customer to select purchase time. When there is a risky option of purchase timing in the model, the contract helps to determine when the best time to buy might be. Time flexibility contracts allow the buyer to monitor the price movements and after that practising the buying for the suitable time under time flexibility, it is possible purchase any time between 0 and time $T$ for the buyer. And also, it lets the company to identify 
the order quantity within a period without indicating the definite purchase time. And then, the company decides on how much to order and when to order for each period to reduce the procurement cost with addition of stock holding cost. Time inflexibility contract, by contrast, declares the quantity to be purchased at a definite time. The firm must define the quantity that it plans to buy at time 0 and when those procurements occur in the forthcoming periods (Li and Kouvelis 1999).

In addition to time flexibility, contracts also include quantity flexibility. Quantity flexibility contracts allow the buyer to delay procurements to a next time and at a favourable quantity and price when a better forecast of the buyer demands are known. Therefore, the agreement helps the purchaser against demand instability such flexibility enables the purchaser to decrease the risk of being understock and overstock ( $\mathrm{Li}$ and Kouvelis 1999). Quantity flexibility contracts especially used by various firms in the computer and electronics industry for instance IBM, DELL, and Samsung since 1991, where demand uncertainties and price fluctuations occur (Sethi et al. 2004). This feature allows the buyer to modify to order within specific limits as demand uncertainty increases or decreases to the point of sale.

A quantity supply chain contract could be expressed as: assume that a company agreed upon a deal of $q$ amounts with a vendor and the commitment is guaranteed an $m \times 100 \%$ quantity flexibility $(0 \leq m \leq 1)$. In that case, the vendor does not obligate the company to buy total $q$ amounts. The company could buy a total of $\varepsilon$ amounts to that vendor, where $(1-m) q \leq \varepsilon \leq q$. At $m=0$, the contract is quantity-inflexible. Then, the company just place an order that will buy in the end.

It is mentioned before that purchase prices change so fast nowadays. This uncertainty in the purchase prices has influenced sourcing activities and estimating the operating costs much more difficult than ever. Risk-sharing contracts offer a much more logical option than the traditional fixed-price contracts. Therefore, price uncertainty and risksharing contracts studied at the literature. For example, Li and Kouvelis (1999) examines 
risk-sharing contract under a price uncertainty. The price is formulated as geometric Brownian motion with a single regime to identify quantity flexible,inflexible, and risksharing agreements. The model solved by a binomial tree The risk-sharing property for a contract is stated with $h(c)$ as follows:

$$
h(c)= \begin{cases}c-\lambda(c-\bar{c}), & \text { if } c>\bar{c}, \\ c, & \text { if } \underline{c} \leq c \leq \bar{c}, \\ c+\lambda(\underline{c}-c), & \text { if } c<\underline{c} .\end{cases}
$$

In the formula, $h(c)$ represents the unit purchase cost, $c$ is the unit price, $\bar{c}$ and $\underline{c}$ are constants, and the risk-sharing ratio shown as $\lambda \in[0,1] . \lambda$ displays a risk-sharing rate that the supplier shares the uncertainty to the buyer as the unit price increases above $\bar{c}$. Besides, $\lambda$ displays a rate that the buyer shares the risk to supplier as the unit price falls below $\underline{c}$. And $\lambda=0$ represents without a risk sharing agreement.

According to the Li and Kouvelis (1999) works, under a risk sharing agreement, supplier and buyer agrees a risk-sharing percentage and then quote a price. After a while passed, when the supplier delivers the goods, the purchase price of that goods may be change than the agreed price because of the supplier's volatile production cost for instance. As the price of the commodity could go up or go down than the agreed value, risk-sharing agreement helps to supplier and buyer to share the unpredictable difference between agreed price and the purchase price. For example, a contract value of the goods is $\$ 50$ per each unit and the risk-sharing percentage with the supplier and buyer is $70 \%$ and $30 \%$. At the delivery time, the price raised to $\$ 80$. If supplier delivers the goods at $\$ 50$ per each unit, supplier loses $\$ 30$ per each unit. If buyer pays for the goods at $\$ 80$ per each unit, the buyer could not get an advantage from the contract. Since, buyer's risk share ratio is $30 \%$, the buyer's final pay-off should be $\$ 59[\$ 50+\$(80-50) \times 30 \%]$. As a result, buyer still gets some benefits from the contract and the supplier compensates its over cost. Conversely, if the price decreases to $\$ 40$ at the delivery time, buyer should pay 
$\$ 47[\$ 50+\$(40-50) \times 30 \%]$ instead of $\$ 40$. That is, buyer pays lower than the contract price, whereas supplier also gets benefit. Therefore, risk-sharing agreement provides win-win opportunity to both suppliers and the buyers.

\subsection{Regime Switching Process}

Throughout the time, economical and financial variables behaviour could change in terms of its mean and volatility. If the behaviour change once, usually it is called as structural break. Or it may change for a period of time and return back to its original behaviour or switching to another type of behaviour which is expressed as regime switch (Cheung and Erlandsson 2005). A stochastic process is said to be regime switching if its behaviour is determined by different models (different regimes) during different time periods. In this section, it is explained processes in which change randomly between regimes.

Economic depressions, wars, important changes in the policy of government, changes in the market trends or changes in the business mechanism leads to drastic modifications in the behaviour of series (Goutte and Zou 2011). Figure 2.1 displays an illustration for the switch. The behaviour of the series changes at around Jan/04. As seen from the plot, the series become much more volatile than previously. For this case, it is logical to group the data into different time periods and forecast models for those periods. These models should let the whole data to predict the future value and also the model should be flexible. Markov regime-shifting model is a good way to enable these properties. 


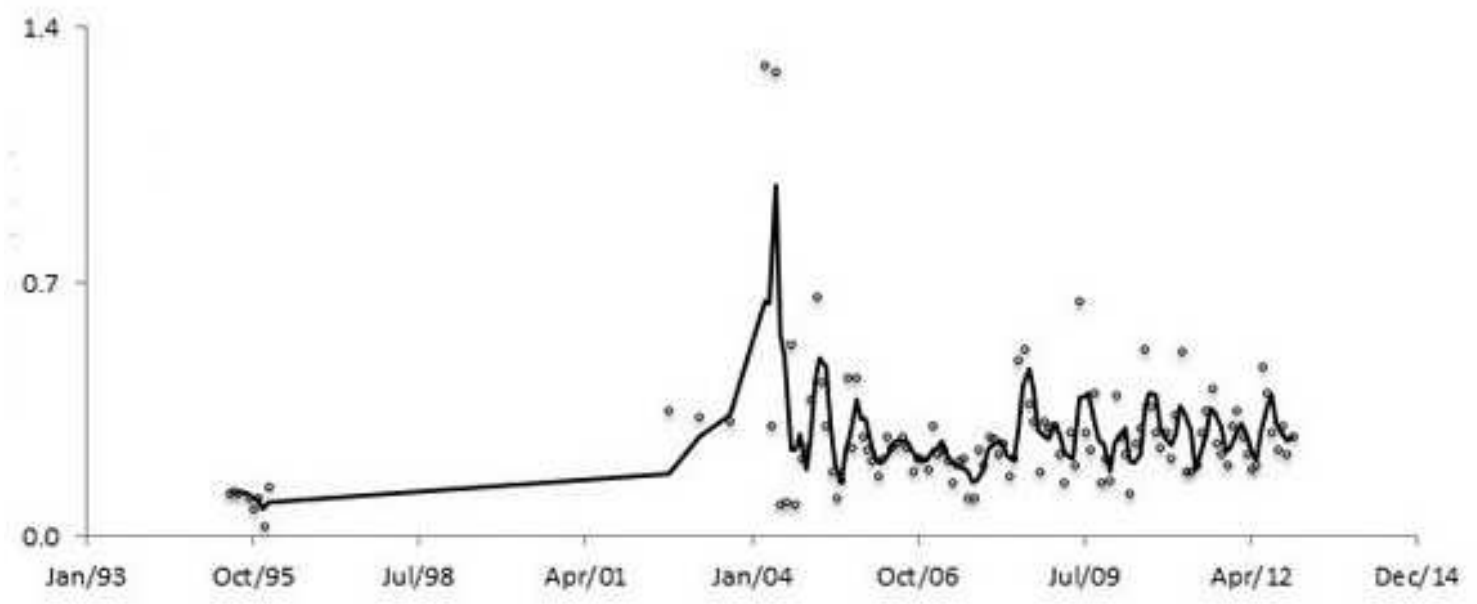

Figure 2.1: A time series with a regime switch (Marin et al. 2014)

Exchange ratio, is the value of a nation's money with respect to the other nation's money, one of the most significant subject in international economics and policy making. Exchange rate switches affect asset prices. Furthermore, investors take into account the exchange rate fluctuations impact on their international portfolios. Governments and central banks also care about its effect for the prices of export/imports, domestic currency value of debt payments, international reserves and domestic inflation values.

Hamilton's (1990) Markov regime-switching representation is a good method for examining exchange rate motion, knowing the fact that the real world economics changes from regime to regime due to the different reasons that mentioned previously. Many financial time series, stock prices, gasoline prices, interest rates, exchange rates, product life cycles of high technology good behaviours cannot be modelled by linear models. To accomplish that problem, regime switching models are used (Yuan 2011). Regimeswitching allows to a variable having different processes with different mean and variance values on a duration of a time. Each process follows a Markovian property which is going from one regime to the other based on the probability of present regime process (Engel and Hamilton 1990). 


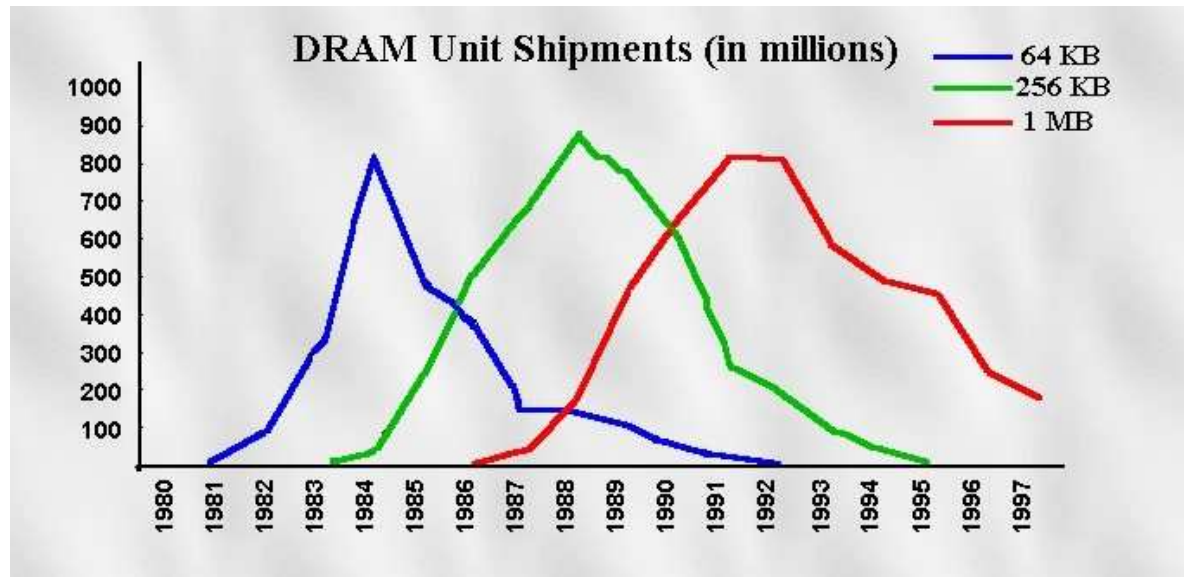

Figure 2.2: Memory card supply history (Bollen 1999)

Seasonal demand alterations are observed for gasoline, electricity, and natural gas. For instance, requirement of the electricity increases summer in Spain, Also, both price and demand of the gasoline are raised throughout the summer in USA. Furthermore, demand of the natural gas is increased particularly during winter in North America.

Several real option practices are using to model uncertainty for different life cycles of a product. For example computer memory cards have increasing demand when they are first introduced to the market. And then, they have a decreasing demand period because of the new cards with excessive capacity. Figure 2.2 illustrates that example for different memory card capacities (Bollen 1999). Demand changes over the a product life cycle and cause managerial challenges. For this type of product, a simple stochastic process may not be appropriate.

\subsubsection{Properties of Markov Switching Model}

The space of probable events is divided into $m$ states. Changing the place of a variable between different states are ruled with a Markov process. Markov property is defined as follows: 


$$
P\left(x<a_{t} \leq y \mid a_{1}, a_{2}, \ldots, a_{t-1}\right)=P\left(x<a_{t} \leq y \mid a_{t-1}\right)
$$

It should be known a probability of staying the existing and moving to the other regime for a variable if it has a Markov regime-switching process behaviour. These probabilities are shown by a transition probability matrix (Bollen 1998):

$$
P=\left[\begin{array}{cccc}
p_{11} & p_{12} & \cdots & p_{1 m} \\
p_{21} & p_{22} & \cdots & p_{2 m} \\
\vdots & \vdots & \ddots & \vdots \\
p_{m 1} & p_{m 2} & \cdots & p_{m m}
\end{array}\right]
$$

$p_{i j}$ : probability of jumping from regime $i$ to $j$.

For instance, let $m=2$. The unobserved state variable, expressed as $v_{t}$, follows according to a Markov process with the probabilities below (Bollen 1998):

$$
\begin{aligned}
& \operatorname{Prob}\left(v_{t}=1 \mid v_{t-1}=1\right)=p_{11}, \\
& \operatorname{Prob}\left(v_{t}=2 \mid v_{t-1}=2\right)=p_{22}, \\
& \operatorname{Prob}\left(v_{t}=2 \mid v_{t-1}=1\right)=1-p_{11}, \\
& \operatorname{Prob}\left(v_{t}=1 \mid v_{t-1}=2\right)=1-p_{22} .
\end{aligned}
$$

$p_{11}$ is the probability of staying in trend 1 , known that a variable was in trend 1 throughout the last term, and $p_{22}$ express the probability of being in trend 2 , known that a variable was in trend 2 through the last term, respectively.

Since at any given time the variable must be one of the $m$ states, it must be true that

$$
\sum_{j=1}^{m} p_{i j}=1 \forall i
$$

$\pi_{i}$ is the probability of being presently at regime $i$. Given $\pi_{i}$ and $P$, the probability of for the following term is forecasted as :

$$
\pi_{i+1}=\pi_{i} P
$$


The probabilities for $n$ step into the future will be given by :

$$
\pi_{i+n}=\pi_{i} P^{n}
$$

The Markov switching approach is useful when a series thought to experience shifts from one behaviour to another and back again.

\subsubsection{Exchange Rate Regime Switching Process}

The price of a merchandise always holds in the long run based on the purchasing power parity theorem. Hence, exchange rates should be constant under some assumptions (Lo and Morley 2015). However, a few studies become unsuccessful to reject the null hypothesis in exchange rates. In order to examine this void, Bergman and Hansson (2005) provide a model that have a Markov regime-switching property model which allows shifts between two regimes. In the study, the currency exchange rates of 6 countries are used. The Markov switching probabilities are acquired with the maximum likelihood estimation. The outcomes are displayed at Figure 2.3.

\begin{tabular}{lllllll}
\hline Parameter & UK & France & Germany & \multicolumn{1}{c}{ Switzerland } & \multicolumn{1}{c}{ Canada } & Japan \\
\hline$\mu_{1}$ & $3.554(0.550)$ & $6.131(0.604)$ & $6.569(0.733)$ & $2.390(0.726)$ & $1.693(0.230)$ & $-0.370(0.681)$ \\
$\mu_{2}$ & $-5.096(0.549)$ & $-2.845(0.409)$ & $-2.676(0.487)$ & $-6.556(0.775)$ & $-0.306(0.249)$ & $-8.932(1.157)$ \\
$\phi$ & $0.928(0.027)$ & $0.904(0.020)$ & $0.888(0.023)$ & $0.958(0.027)$ & $0.922(0.021)$ & $0.871(0.027)$ \\
$\sigma^{2}$ & $10.118(1.698)$ & $7.706(1.293)$ & $10.719(1.799)$ & $13.513(2.268)$ & $1.644(0.276)$ & $15.879(2.665)$ \\
$p_{11}$ & 0.672 & 0.679 & 0.682 & 0.792 & 0.952 & 0.911 \\
$p_{22}$ & 0.690 & 0.833 & 0.830 & 0.716 & 0.944 & 0.817 \\
\hline
\end{tabular}

Note: Standard errors in parentheses and $p$-values in square brackets.

Figure 2.3: Markov regime-switching process for two state (Bergman and Hansson 2005)

From Figure 2.3 it can be seen that, the model divides the exchange rates into two regimes. Regime $1\left(\mu_{1}\right)$ is positive for all countries except Japan means a drop of the 
domestic currency against the dollar. $\mu_{2}$ is negative for all countries, stands for a domestic currency appreciation against the dollar.

The probabilities of continuing in the same regime for the next period $p_{11}$ and $p_{22}$ are low for the UK, France, Germany, and Switzerland indicating periodic shifts from one regime to another in the currencies of those countries. At the end, the authors used the proposed model to make comparisons with the estimations generated by a random process. They find that the model built predictions having the lowest mean squared errors that is statistically significant.

In this project, a flexible quantity with risk-sharing supply network agreement is proposed under demand and price uncertainties. The contributions of this project are threefold: First, to provide a multi-period mathematical model to solve the procurement decisions problem of the buyer considering with stochastic demand and random price. Second, to illustrate a realistic application of this model within the context of risksharing supply chain contracts with regime switching models for exchange rates. Finally, to present some empirical analyses for the effect of changes in the problem parameters on the resulting solutions. As will be presented in the literature section, none of the studies consider a flexible and a risk-sharing supply contract with random demand and random price while modelling the exchange rates by regime switching approach. 


\section{Chapter 3}

\section{Literature Review}

Studies of supply contracts focus on costs of components, ordered amount, delivery date, inventory allocations and the other variables ( $\mathrm{Li}$ and Kouvelis 1999). The problem parameters such as demand and price of the products can be deterministic or stochastic (Munson et al. 2012).

There are assorted studies in the literature on management science area considering stochastic processes. For the project concept, literature studies can be categorized into three parts. In the first part, we emphasize on financial and real option valuation methods for two and $n$-regimes. In the second part, we focus on supply chain contracts and lastly, papers about regime switching studies for exchange rates are mentioned.

\subsection{Valuation Methods of Financial and Real Options}

Some fundamental studies that covering the valuation methods of financial and real options for two or $n$-regimes are followings: Bollen (1998), Bollen (1999), Nembhard et al. (2005) and Wahab and Lee (2009). One of the earlier studies considering valuing financial options in two-regime is Bollen (1998). In this study, variables are defined to 
represent the probability of switching regimes. Parameters are different for each regimes. And, the returns are assumed as normally distributed in both regimes. Bollen (1998) suggested a pentanomial lattice to value an American and European options for the regime-switching models. Each trend is shown with a trinomial tree for the trends at the pentanomial tree. To merge both regimes in one lattice and decrease the number of nodes, step sizes are adjusted of both regimes into a 1:2 ratio.

In addition to determining the value of a financial asset, some studies also suggested modelling manufacturing or project operations using real options. Bollen (1999) determines an option valuation technique for high technology and newly improved products such as semi-conductors that have different life cycles which means a process can not be proper for dynamically changing demand. To model accurately for these kind of products, demand should be taken differently in the product life cycles instead of a constant expected growth rate. Real option concept is considered for changing a project's capacity in the study. Problem solved with the pentanomial lattice using dynamic programming to give a price the project and also production capacity changing options. In the analyses, it is showed that single regime model that ignores the product life cycle undervalues the actual results.

Nembhard et al. (2005) propose a dynamic method to estimate the value of real options under uncertain currency exchange rate for a global manufacturing company. Manufacturing enterprise aim is maximizing the profit. The company has a flexible option to decide on suppliers and facility locations with a manufacturing time pause. In the literature, real options and financial options are applied right away while for the sophisticated productions that assumption can not used due to the fact that production takes a long time. They assume exchange rates follow geometric Brownian motion. Firstly, the pentanomial lattice is formulated. However, with the lattice method calculations are increased dramatically when there are more than two states variables in the model. Therefore, they suggest a simulation approach to simplify evaluating flexibility models 
for various variants.

A variable can has more than 2 trends. Wahab and Lee (2009) define a regime switching procedure with $n$ states to examine swing option valuation for gasoline industry under price uncertainty when states are defined by geometric Brownian motion. Similar to financial options, swing is a kind of agreement that an owner purchases an amount of energy at a price while having flexibility in the amount of quantity and the price. A limitation is set how much that energy will cost and how many times during the month the option holder can swing the quantity of energy bought. The net present values are shown with nodes in the lattice. The authors stated that provided lattice method can be implemented to several supply contracts.

\subsection{Supply Chain Contracts}

In addition to considering the valuation methods of financial and real options for two or $n$-regimes, some studies also embodies several types of supply chain contracts. These papers can be listed as follows: Bassok and Anupindi (1997), Gurnani and Tang (1999), Tibben-Lembke (2004), Sethi et al. (2004) , Li et al. (2009), Munson et al. (2012), Feng et al. (2013), Hu et al. (2013b), Albeniz and Simchi-Levi (2015), Hochbaum and Wagner (2015).

Bassok and Anupindi (1997) describe a purchasing plan for a product with periodic review and stochastic demand for minimum commitment contracts. They derive a model for decreasing the overall expenditures of the purchaser. The buyer signs a contract that can order any amount for any time. Based on the contract, the vendor offers a discount. A supplier gives a plan of (price and quantity) pairs. When the agreed order amount goes up, the price decreases. They formulate the problem in terms of a dynamic model.

In the paper of Gurnani and Tang (1999) the best order plan to a retailer within a selling season is determined for a profit maximization. Retailer has two instants to 
give an order before season starts. Demand is assumed as uncertain. To improve the demand forecast, retailer observes market trends between first and second order. Since the retailer observes the market, second instant information is more accurate than the first one. So, retailer wants to postpone the order before the second season. Moreover, manufacturing costs are uncertain due to the fluctuations in currency exchange rate and shortage inventory. They developed a newsvendor model to find optimal order quantity for each two instants. Demand information quality range from the market is also considered (i.e. from worthless to perfect information level). Joint distribution of demand and information is normally distributed.

A purchasing policy that minimizes the expected profit for $N$-period is determined for the long term quantity flexible supply contracts in the paper of Tibben-Lembke (2004). The model is solved with dynamic programming. Over the contract duration, the buyer guarantees to purchase a minimum amount. Therefore, purchaser gets a better price in the long-term contract. It is assumed that demand is random and all unmet demands are backlogged. Demand is modelled by normal distribution. There are so many variables that make the model complicated and make the completion time increases. Therefore, they also build an heuristic method for the proposed policies. It is stated that when the demand is stochastic, having flexible options leads to gain much more benefit.

Sethi et al. (2004) build a model for a single and a multi-period flexible quantity contract to find best quantity order amount in the beginning of a time-period. In the contract feature, purchaser has a right to increase its quantity order. And also, the buyer can revise the order amount based on the demand forecast before the final purchase. Authors also study the effect of information level on the purchasing decisions. They use two alternative price (high and low) that follows geometric Brownian motion.

In the management science literature, so many supply contract models are investigated. In Li et al. (2009), both long-term and short-term agreements are compared to choose the right supplier under dynamic demand process. Signing long-term agreement 
ensures stable and reliable price and quality in the environment of upward or downward market price trend. With the short-term contract, the buyer takes the benefit of best price for each period. But, the short-term price is too stochastic because of the dynamic movements of supply and demand on the market. This study revealed that when the variance of the price is high, long-term contracts decrease the expected cost.

Munson et al. (2012) analysed commitment and option contracts with time flexibility. Purchase cost assumed to be varied stochastically over the length of the contracts. Timing and purchase price expectation strategies are combined for the buyer's (retailer) decision. Profit maximization model is formulated. Proposed model extended for multiple supplier cases. In these cases, the price processes for different suppliers may vary due to the exchange rate fluctuation impact and different raw material costs (e.g. aluminium vs. steel).

Feng et al. (2013) work on a market-based adjustable contract problem which is solved by Nash bargaining equilibrium to identify the target price and risk sharing ratio of the contract for single vendor and a buyer. This study has also same risk-share properties with Li and Kouvelis (1999) settings, yet varies in terms of customer and supplier are both risk-averse. The model considers market price uncertainty with supplier's and buyer's production cost variabilities. The risk-sharing mechanism (target price and risk sharing ratio) is not given. Lastly, buyer's operating cost is considered.

Hu et al. (2013b) examines one-period supply network coordination problem between two suppliers and a retailer with stochastic demand and random production output. Optimal solution for the centralized model is presented. Also, leading supplier's and retailer's decisions are formulated for decentralized model. It is argued that simple wholesale and overproduction risk-sharing contract can not decrease the total cost of the network. So, both buy-back and risk-sharing agreements are suggested in addition to a second supplier to maximize the profit.

In a related paper of Li and Kouvelis (1999), Albeniz and Simchi-Levi (2015) provide 
a discrete time dynamic model for supply contract selection of a buyer who has stochastic demand for a period of time. The aim of this study is to generate the best combination of different suppliers according to the prospective contract prices. The authors offer the following contract combinations: A long term constant price contract, spot market and option contracts. Firstly, a replenishment problem of the buyer is solved dynamically. And then, the best contract combination at the beginning of the period is solved. Eventually, the authors display the model on an example that the long term contracts have an advantage of the expected profit.

Hochbaum and Wagner (2015) consider the range contract, which enables a buyer and a supplier to share the cost of a volatile demand and build a win-win position where both firms benefit from decentralization. In a range contracts, the buyer can order any quantity within the range. This form of the contract is suitable for semiconductor industry in high-tech sector which has inflexible production and short-life cycles product. Demand is assumed as random with uniform distribution. They modelled both for the vendor's and the customer's profit maximization.

There are also some papers dealing with uncertainty while determining the optimal purchase amount and time in the contract literature. Various sources of uncertainty are considered. For instance, random demand and supply, uncertainty in the purchase prices, uncertainty in the production output and uncertainty in the exchange rates. Some examples of studies considering changeability are Li and Kouvelis (1999), Kamrad and Siddique (2004), Fotopoulos et al. (2008) and Hu et al. (2013a).

$\mathrm{Li}$ and Kouvelis (1999) propose a dynamic programming model with using the binomial lattice for the valuation of different types of supply chain contracts under a risk-sharing property. Objectives of the model are determining a procurement plan for a company that expected overall cost (purchase and inventory cost), expected net present value, is minimized. Firm both decides on order time and quantity when considering time-inflexible, time-flexible and quantity flexible supply contracts under uncertain 
prices. The authors assumed that the firm's customer future demand is deterministic. It is also assumed that unit purchasing price follows the geometric Brownian motion. Analyses are done for a single and two supplier cases.

Kamrad and Siddique (2004) study on valuing quantity flexible contracts for random exchange rates, revenue sharing, multiple supplier choice, counteraction options. Exchange rates are represented by a standard Brownian motion. The producer forms a combination from multiple suppliers in which the combination of the suppliers have a lower variability from than an individual one. Suppliers are located on different countries. The customer chooses its supplier from that combination during the period. Portfolio theory is used for the risk reduction with using the supplier combinations as a risky portfolio. The customer changes the amount of order based on the volatility of exchange rates throughout the time. In return, suppliers give a penalty for a protection to unexpected changes in the customer's order size. So, supplier gains revenue from these penalties. Suppliers react and protect their rights against customer's order level changing and to exchange rate fluctuations. Supplier's counteraction define as an option. A dual profit maximization problem is developed for the supplier's and producer's option value.

Fotopoulos et al. (2008) study a flexible-time contract under changing prices with deterministic demand. Purchase price process is expressed as geometric Brownian motion. For the supply chain contract, the firm would like to decide the discounted total cost at time $t$ for every order and every quantity for minimizing order and inventory holding costs.

$\mathrm{Hu}$ et al. (2013a) propose a flexible quantity contract that the buyer's order changes between a minimum and a maximum amount. It is accepted that supplier's production output (yield) and demand is uncertain. The paper's objectives are to maximize expected profit that coordinate the centralized and decentralized supply chain networks by proposing a flexible ordering policy with negotiations. For operational decisions, minimum and maximum purchasing quantities for the customer's perspective and production amounts 
for supplier's point of views are determined. It is also assumed that there is one supplier with stochastic production and one buyer with deterministic production with random demand. Flexible ordering policy is modelled for centralized supply chain where supplier and buyer have a coordination. It is showed that flexible ordering policy enhances the total network's profit. For maximizing network's expected profit a new combined agreement (OPR-order penalty and rebate) with revenue sharing contract is developed.

\subsection{Regime Switching Studies for Exchange Rates}

In this project, it is specifically developed a model for a stochastic price market environment while evaluating the flexible risk-sharing supply contract. Since price volatility depends on the changing trends of exchange rates, we also continue to research on another relevant stream which is regime switching studies for exchange rates. Examples of studies dealing with regime switching for exchange rates are Bollen et al. (2000), Bergman and Hansson (2005), Cheung and Erlandsson (2005), Lee and Chen (2006), Goutte and Zou (2011)and Yuan (2011).

Bollen et al. (2000) study capability of regime-switching model for capturing the behaviour of FX. Mean and variance are evaluated for the data by maximum likelihood method for one, two and four regime distributions. Returns are assumed normally distributed in each regimes. Parameters pair are calculated for appreciation and depreciation periods. The results indicate that two or four regime switching models performers well than the single regime model. The paper proved that exchange rate has trends within their processes and a regime-switching evaluation method achieves greater profits than traditional option valuation models.

Bergman and Hansson (2005) suggest regime-switching model allows for multiple switches between two regimes for exchange rates. The Markov switching model estimates are obtained using maximum likelihood estimation. They find that for all six series and for 
forecast horizons up to 4 steps (quarter) ahead, their Markov switching model generates predictions with the lowest mean squared errors which is statistically significant.

In the model of Cheung and Erlandsson (2005) Monte Carlo approach is proposed for overcome the statistical unidentified parameter problem when identifying the distribution of exchange rates with having more than two regimes. It is suggested that data should be increased to enhance the power of Monte Carlo test while detecting the Markov switching dynamics. Analyses resulted that exchanges show a dynamic Markov regime-switching property.

Lee and Chen (2006) use a model to define exchange rate dynamics under a dirty float regime. A dirty floating is occurred by a government which causes to change the direction of the float by selling or buying currencies.Also, stochastic actions made by the central bank leads to a change in market expectations, and therefore the process of the exchange rates. The authors stated that the process of exchange rates can be described by stochastically. They showed with this paper that Markov method is appropriate dirty floating exchange rate regimes which is one of the most well-known exchange rate regime in the world. It is showed that the parameters of exchange rate are state-dependent. This explains the hypothesis of exchange rate process has a regime switching model.

The work by Goutte and Zou (2011) initially present exchange rates with CoxIngersoll-Ross model with regime switching. They calibrate the model based on some real daily foreign exchange rate data and do some comparisons with respect to other non-regime switching model. Findings demonstrate that stochastic exchange rate under regime switching model match the regime-switching duration in which a financial depression occurred between January 2000 and March 2000.

Yuan (2011) presents a forecasting model for exchange rates. The new model corrects two shortcomings of the existing literature. Firstly, existing models tends to be unstable in estimation for regime shifts as financial processes such as exchange rates are usually highly volatile. Secondly, standard Markov switching models using just two trends, 
growth and decline, which is not suitable almost all exchange rates. So, a third regime with no trend is suggested to define the behaviour of exchange rates.

According to the author's knowledge, none of the studies referred in that part considers a flexible and a risk-sharing supply chain contract with random demand and random price while modelling the exchange rates by regime switching approach. 


\section{Chapter 4}

\section{The Model}

This chapter firstly presents the problem definition of the studied project. A multi-period mathematical model is solved for the procurement decisions problem of the Canadian buyer sourcing from USA. The buyer assumed to be encountered with a random demand and also random price due to the exchange rate volatility between Canadian and US dollar. Therefore, a risk-sharing supply contract is applied for the price uncertainties. This contract helps to compensate a supplier for the decreasing monetary value of the price with a buyer. And also helps the buyer when the currency appreciates. Secondly, a comprehensive information about regime switching exchange rate model is given. And then, $n$-period lattice approach is explained. Lastly, a dynamic programming model is generated for the valuation of contracts. In the supply chain contract literature, $n$-period procurement problems and a regime switching model have never been used for the flexible quantity risk sharing agreements under price uncertainty.

\subsection{Problem Definition}

Let's consider a product which is procured from USA paying US dollar by a Canadian buyer and all costs are converted into Canadian dollar. The US supplier is flexible to send any quantity to the buyer. That is, the vendor has unlimited supply quantity of a 
product. The demand per period $D$ is assumed to be a normal distribution with mean, $\mu$, and variance, $\sigma^{2}$. The inventory model is base-stock policy ( $S$-policy). The behaviour of the product price is changed due to the volatility of the exchange rates. The exchange rate has a regime-switching process with multiple trends ( $n$-regimes). Each trend is defined by a geometric Brownian motion. The problem is modelled under a risk sharing agreement, the supplier and the buyer agrees a risk-sharing ratio, $\lambda$, and quote a price. After a period of time passed, when the supplier delivers the goods, the purchase price of these goods may be changed than the agreed price because of the volatility of the exchange rates or supplier's production expenses.

As the value of the commodity can go up or down from the agreed price, risk-sharing agreement helps vendor and buyer to share the uncertain difference among agreed price and the spot-market value. The objective is to evaluate and compare the price of the product over different discrete-time periods to obtain best order-up-to level with a net present value given that the inventory level at period $t$ before ordering $x$, the purchase price is $c$, and that the regime is $i$.

Here is the some assumptions for the problem:

- linear holding cost $h$ per unit per period

- stochastic demand with pdf $\phi(\cdot)$ and $\operatorname{cdf} \Phi(\cdot)$

- possible values of prices: $\left\{c_{1}, c_{2}, \ldots, c_{k}\right\}$, where $c_{1} \geq 0$, and $c_{i+1}>c_{i} \forall 1<i<k-1$

- price follows a Markovian transition with transition matrix $\Pi=\left\{\pi_{i j}\right\}$

- Set-up cost is negligible because nowadays all communication activities are conducted via e- mail or telephone (Bassok and Anupindi 1997, Fotopoulos et al. 2008, Munson et al. 2012, Hu et al. 2013b)

- No lead times (Haksoz and Seshadri 2007, Li et al. 2009, Munson et al. 2012)

- Unsatisfied demand is lost (Hu et al. 2013a, Hu et al. 2013b) 
- No capacity restrictions since supplier is flexible, so it can be possible to order any quantity (Gavirneni 2004)

\subsection{Regime-Switching Exchange Rate Model}

For that part, a lattice model is introduced to model the process for an exchange rate that has $n$-regimes.

A stochastic process is said to be regime switching if its behaviour is determined by different models (different regimes) during different periods.

In a one-regime approach, the stochastic process is defined with a probability distribution such as Black-Scholes-Merton model for a profit $P$ price of the stock that can be described by a normally distributed geometric Brownian motion as follows (Black and Scholes 1973):

$$
P \sim N\left(\mu, \sigma^{2}\right)
$$

For this project, it is studied a multiple regime model that is regime $i$ is distributed normally with a drift $\mu_{i}$, and standard deviation $\sigma_{i}$. The $n$-regime model could be defined as follows:

$$
\begin{aligned}
& P_{t} \mid \Phi_{t-1} \sim N\left(\mu_{i}, \sigma_{i}^{2}\right) \text { with probability } p_{t}^{i}=\operatorname{Pr}\left(v_{t}=i \mid \Phi_{t-1}\right), \\
& \quad \text { and } \sum_{i} p_{t}^{i}=1 .
\end{aligned}
$$

Where $P a_{t}=\ln \left(X_{t} / X_{t-1}\right)$ and $X_{t}$ represents a FX (currency exchange rate) in terms of US dollars for the foreign currency. The detailed information about Equation 4.2 was presented at Section 2.3.1 Properties of Markov-Switching Model. n-regime model, has $n^{2}$ transition probabilities shown as:

$$
\operatorname{Pr}\left(v_{t}=i \mid v_{t-1}=j\right) \text { for } i, j=1,2, \ldots, n,
$$

The transition from one state to the other is driven by a transition probability matrix. Transition probabilities are known as regime persistence parameters, the other words they 
can be defined as probability of remaining the existing and moving to the other regime for a variable if it has a Markov regime switching behaviour.

\subsection{Lattice Approach}

As Lattice (tree) method provides a simplicity and a flexibility in the mathematical calculations, they have been used so frequently. The main objective is to construct a discrete-time tree for the prospective worth for a random variant during time steps. Continuous distribution process such as geometric Brownian motion can be represented in the lattice by dividing the total time duration into equal fine discrete intervals. This process is called discretization. For instance, a financial option has a finite expiry date of $X$ years. The tree is generated by an integer number, $m$, with time steps, $y$. Then, the duration of each steps is $X / y$. For example, an evaluation process of an option starts at the end of the due date and come back to the current day, recursively. For the end nodes, the value of an option is the payoff, whereas for interim nodes, the value of the option can be formulated as the sum of the present time payoff plus the expected discounted payoffs for the future periods.

In the literature section, it is explained that there are various studies that use for example a binomial lattice to value an option for a single regime with a geometric Brownian motion, as well as for stochastic processes. Intuitively, one may think that a binomial lattice is modelled with each regime with 4 branches (quadrinomial lattice) are enough to model randomly changing distributions. However, this four branch method is not efficient. The reason for this inefficiency is explained as the branches can not be generated properly as the time passes.

To solve this problem, a trinomial lattice is substituted for one of the binomial lattice with resulting an extra fifth branch. Therefore, the tree has equally 5 branches. The center branch is shared by two trends (Bollen 1998). The flexibility of a five branch 
lattice is that the streams could be located equally whereas remaining to preserve the original mean and variance of the variable by choosing appropriate branch probabilities. It also gives opportunity for wider branches with positive probabilities. A lattice method is generated to describe the behaviour of a variable that has a different regime switching models for multiple regimes that each regime is defined with a geometric Brownian motion.

According to the study of Bollen (1998) every regime is shown with a trinomial lattice that the center stream is shared in the tree method. To decrease the lattice points unite with modifying the jump sizes (Figure 4.1). To make a decision for the which regime's step size should be changed, the branch probabilities and step sizes for the regimes should be calculated. This process is called as adjusting of the step size. The jump size for the regimes are calculated using equation (4.4), which is similar to equation (9) in Bollen (1998):

$$
\hat{\phi}_{i}=\sqrt{\sigma_{i}^{2}(\Delta t)+\mu_{i}^{2}(\Delta t)^{2}}, \quad i=1,2, \ldots, n
$$

$\mu_{i}$ and $\sigma_{i}$ represent drift and volatility for trend $i ; \Delta t$ denotes the time interval among two discrete sections of the tree (Bollen 1998). In order to maintain the positive conditional branch probability, the step size $\Delta t$ can be chosen sufficiently small.

Wahab and Lee (2009) modelled a $n$-trend tree. The following properties are generated based on their paper. Assume $\hat{\phi}_{1}, \hat{\phi}_{2}, \ldots, \hat{\phi}_{n}$ are the jump sizes for rends. Firstly, index the trends again such as $\phi_{1}<\phi_{2}<\phi_{3}<\ldots,<\phi_{n}$ holds. After re-indexing the regimes, we set $\phi_{k}=\hat{\phi}_{i}$ for $k=1,2,3, \ldots, n$ such that $\phi_{1}<\phi_{2}<\phi_{3}<\ldots,<\phi_{n}$ holds, and secondly $\phi=\max \left\{\phi_{1}, \frac{\phi_{2}}{2}, \frac{\phi_{3}}{3}, \ldots \frac{\phi_{n}}{n}\right\}$ (Wahab and Lee 2009). Let $\phi=\frac{\phi_{k}}{k}$ (i.e., $\left.\frac{\phi_{k}}{k}>\frac{\phi_{j}}{j}, \forall j \neq k\right)$. Third, modify the jump size for the trends $\phi_{j}$ such as:

$$
\widetilde{\phi}_{j}= \begin{cases}\phi_{k}, & j=k, \\ j \frac{\phi_{k}}{k}, & j \neq k .\end{cases}
$$




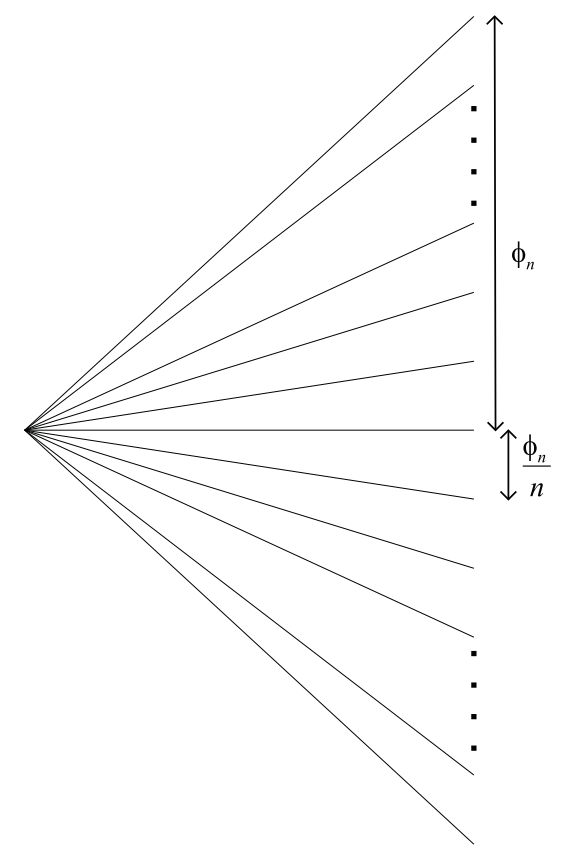

Figure 4.1: Multinomial lattice-one step

Regimes with step size $\phi_{j}$, i.e., $j \neq k$, are build with a trinomial tree. The highest, center, and lowest conditional branch probabilities for tree branches with trend $j=1,2,3, . ., n$ are as follows (Wahab and Lee 2009):

$$
\begin{aligned}
\pi_{\widetilde{\phi}_{j}, u} & =\frac{e^{\mu_{j} \Delta t}-e^{\left(-\widetilde{\phi}_{j}\right)}-\pi_{\phi_{j}, m}\left(1-e^{\left(-\widetilde{\phi}_{j}\right)}\right)}{e^{\left(\widetilde{\phi}_{j}\right)}-e^{\left(-\widetilde{\phi}_{j}\right)}} \\
\pi_{\widetilde{\phi}_{j}, m} & =1-\frac{\phi_{j}^{2}}{\left(\widetilde{\phi}_{j}\right)^{2}}, \\
\pi_{\widetilde{\phi}_{j}, d} & =1-\pi_{\widetilde{\phi}_{j}, u}-\pi_{\widetilde{\phi}_{j}, m},
\end{aligned}
$$

When regime $\phi_{k}$, i.e., $j=k$, a binomial lattice is used for this trend. Because when $j=k$ the center stream probability becomes zero. In this case, the expressions for the branch probabilities can be simplified from Equations (4.6)-(4.8) and they are given as:

$$
\begin{aligned}
& \pi_{\widetilde{\phi}_{j}, u}=\frac{e^{\mu_{j} \Delta t}-e^{-\widetilde{\phi}_{j}}}{e^{\widetilde{\phi}_{j}}-e^{-\widetilde{\phi}_{j}}}, \\
& \pi_{\widetilde{\phi}_{j}, d}=1-\pi_{\widetilde{\phi}_{j}, u},
\end{aligned}
$$


For the purpose of giving a start with the tree, the jump sizes of each trends and conditional branch probabilities are calculated with Equations (4.4)-(4.10) and then, lattice is built for a specific date. At the end, price of a product can be determined using the exchange rate computed at each node.

\subsection{Valuation of Contracts}

An option valuation can be defined as a price to buy the right of a related option. The other words, value of an option is a function that depends on the time value of the asset that can be changed due to the volatility. Binomial tree method is one of the most fundamental and simple way to value the options such as American and European for a discrete-time period. An American option owner possess a right to exercise the American option every time, while an European owner possess to exercise the option at just its expiration time (Black and Scholes 1973). In the binomial tree method a stochastic process for a variable can be move to either up or down with a certain probability during a discrete time period which is the total life of the option.

Let's think a binomial tree in which a stochastic variable has a single trend process. One should first calculate the option values at the final (terminal) nodes and then move from back to the beginning by calculating the expected value of the forward nodes. Note that final (terminal) nodes are the expiration date of the option. At each final node for an European option can be found as follows: $\operatorname{Max}[0$, Exercise value $]$. For the forward nodes the option value is : $\operatorname{Max}[0$, expected discounted payoff]. Expected discounted payoffs can be calculated with using the probability percentages of moving up or down for the underlying asset. The same process is repeated from each final node to the current time. On the other hand, there is a right to hold the option or exercised it until due date for an American option owner (Wahab and Lee 2009). Therefore, the value of the forward nodes can be formulated as: Max[exercise value, expected discounted payoff from early 
exercise] for each node. The value of the terminal nodes are same with the American option.

On the other hand, regime probabilities and regime-switching likelihood for every nodes lead to a complexity while calculating the discounted expected value for the regimeswitching models. To handle this difficulty, conditional option values for the nodes with related trends are used. Conditional information of one node is coming from the preceding state. Therefore, it can be calculated from the backward procedure, and at the end there is a one option value for every trend. Moreover, the conditional probabilities rely on the transition probability matrix. The reason is that prospective regime probabilities are identical with the conditional transition probabilities.

Two regimes are used to show the algorithm. The following Figure shows two-regime process for an exchange rate. In this Figure, $\phi$ is the step size of the regime, subscript $i=1,2$ of $\phi$ represents two regimes, and $l$ indicates the level of the exchange rate (branch position).

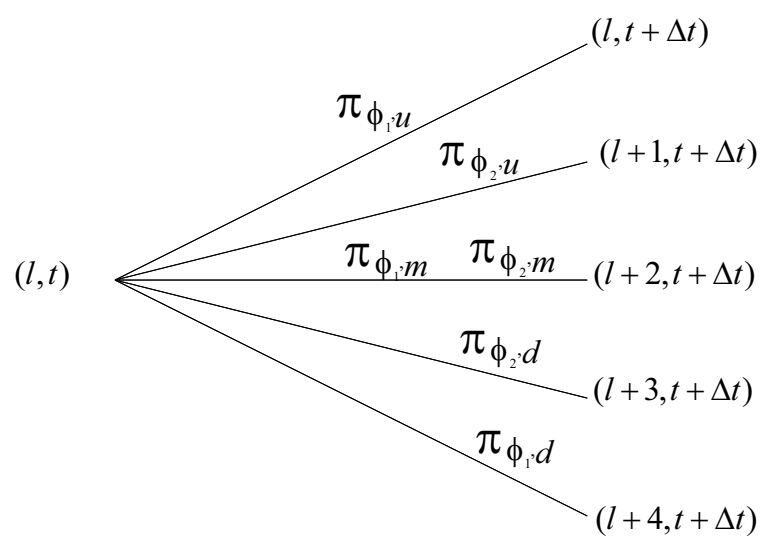

Figure 4.2: Two-regime process for an exchange rate

"Base-stock policy" (S-policy) is applied. This policy says that whenever the stock is less than $S$ we palace an up to $S$ amount of order . That is, the maximum inventory level is $S$; with the lost sale we have a lower bound of 0 . 
Suppose that the buyer is unable to segment the market into submarkets where each market serves a different group of consumers and the seller prices the product using a fixed marginal profit. In other words, if the purchase price is $c$, the price will be set at $(1+\alpha) c$, where $\alpha>0$ is the marginal profit.

Suppose that demand for per period, $D$ has a distribution with continuous probability density function $f(\cdot)$. Also, $r$ represents a constant interest rate per year. Decision period is one month, which is denoted by $\Delta t$, which is $1 / 12$ year. The holding cost per unit per period is $h$. Let $z(x, i, c, t)$ denote the optimal net present value given that the stock level at period $t$ when ordering $x$, the purchase price is $c$, and that regime is $i$. The best order-up-to level $y$ for each scenario is needed to be obtain. Following recursive equations are generated:

$$
z(x, 1, c, t)=\max _{y \geq x}\{c x+G(y, 1, c, t)\}
$$

where

$$
\begin{aligned}
G(y, 1, c, t)= & c(1+\alpha) E[\min \{D, y\}]-c y-H(y) \\
& +e^{-r \Delta t} \gamma_{11} \pi_{\widetilde{\phi}_{1}, u} E\left[z\left((y-D)^{+}, 1, c e^{\widetilde{\phi}_{1}}, t+\Delta t\right)\right] \\
& +e^{-r \Delta t} \gamma_{11} \pi_{\widetilde{\phi}_{1}, m} E\left[z\left((y-D)^{+}, 1, c, t+\Delta t\right)\right] \\
& +e^{-r \Delta t} \gamma_{11} \pi_{\widetilde{\phi}_{1}, d} E\left[z\left((y-D)^{+}, 1, c e^{-\widetilde{\phi}_{1}}, t+\Delta t\right)\right] \\
& +e^{-r \Delta t} \gamma_{12} \pi_{\widetilde{\phi}_{2}, u} E\left[z\left((y-D)^{+}, 2, c e^{2 \widetilde{\phi}_{1}}, t+\Delta t\right)\right] \\
& +e^{-r \Delta t} \gamma_{12} \pi_{\widetilde{\phi}_{2}, m} E\left[z\left((y-D)^{+}, 2, c, t+\Delta t\right)\right] \\
& +e^{-r \Delta t} \gamma_{12} \pi_{\widetilde{\phi}_{2}, d} E\left[z\left((y-D)^{+}, 2, c e^{-2 \widetilde{\phi}_{1}}, t+\Delta t\right)\right]
\end{aligned}
$$

where

$$
E[\min \{D, y\}]=\int_{-\infty}^{y} D f(D) d D+\int_{y}^{\infty} y f(D) d D
$$

and the holding cost

$$
H(y)=h \int_{0}^{y}(y-D) f(D) d D
$$


It is assumed that there is no salvage value, i.e., $z(y, 1, c, T+\Delta t)=0$ for all $y$ and $c$. Similarly, if regime is 2 , we have

$$
z(x, 2, c, t)=\max _{y \geq x}\{c x+G(y, 2, c, t)\}
$$

where

$$
\begin{aligned}
G(y, 2, c, t)= & c(1+\alpha) E[\min \{D, y\}]-c y-H(y) \\
& +e^{-r \Delta t} \gamma_{21} \pi_{\widetilde{\phi}_{1}, u} E\left[z\left((y-D)^{+}, 1, c e^{\widetilde{\phi}_{1}}, t+\Delta t\right)\right] \\
& +e^{-r \Delta t} \gamma_{21} \pi_{\widetilde{\phi}_{1}, m} E\left[z\left((y-D)^{+}, 1, c, t+\Delta t\right)\right] \\
& +e^{-r \Delta t} \gamma_{21} \pi_{\widetilde{\phi}_{1}, d} E\left[z\left((y-D)^{+}, 1, c e^{\widetilde{\phi}_{1}}, t+\Delta t\right)\right] \\
& +e^{-r \Delta t} \gamma_{22} \pi_{\widetilde{\phi}_{2}, u} E\left[z\left((y-D)^{+}, 2, c e^{2 \widetilde{\phi}_{1}}, t+\Delta t\right)\right] \\
& +e^{-r \Delta t} \gamma_{22} \pi_{\widetilde{\phi}_{2}, m} E\left[z\left((y-D)^{+}, 2, c, t+\Delta t\right)\right] \\
& +e^{-r \Delta t} \gamma_{22} \pi_{\widetilde{\phi}_{2}, d} E\left[z\left((y-D)^{+}, 2, c e^{-2 \widetilde{\phi}_{1}}, t+\Delta t\right)\right]
\end{aligned}
$$

Denote the optimal policy by $S_{t}(i, c)$, where period $t=1, \cdots, T$, regime $i=1,2$, and purchase cost is $c$. Define $S(i, c)$ as the number which maximizes

$$
V(i, c, y)=c(1+\alpha) E[\min \{D, y\}]-\left(c-e^{-r} E[c \mid i]\right) y-H(y)
$$

$E[c \mid i]$ represents expected cost for the following term knowing that $i$ is the present regime and the current cost is $c$. 


\section{Chapter 5}

\section{An Example and Sensitivity}

\section{Analyses}

In this chapter, the proposed model is presented in Chapter 4 with a numerical example and several sensitivity analyses. The analyses include changes in gross margin, mean and standard deviation of the demand, holding cost, risk-sharing ratio, lower and upper price. In addition, changes in the standard deviations of the exchange rate for regime 1, regime 2 and a single regime models are also investigated.

\subsection{Numerical Example}

Figure 5.1 shows the exchange rate in Canadian dollar (CAD) per US dollar (USD) during the period of August 5, 2010 and October 17, 2011. Figure 5.2 shows two regimes of the exchange rate and smoothed probabilities. Table 5.1 provides the daily estimated parameters for both regimes. Parameters are forcasted by maximum likelihood assuming normal distribution returns for each regime. The same exchange rate data is used to fit into a single Brownian motion and Table 5.2 shows the daily estimated parameters. When estimating the parameters, the null hypothesis is that each parameter value is 0 and the $\mathrm{p}$-value reflects the reliability of the null hypothesis. 


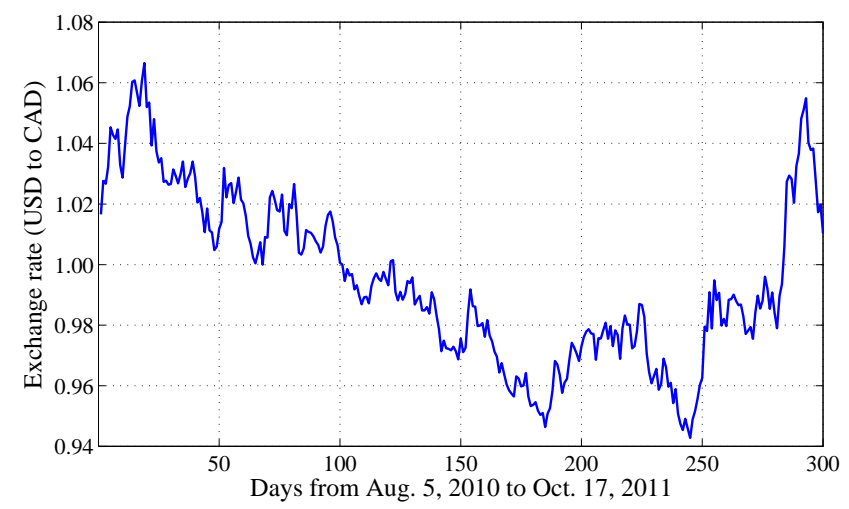

Figure 5.1: Daily exchange rate in CAD per USD from August 5, 2010 and October 17, 2011

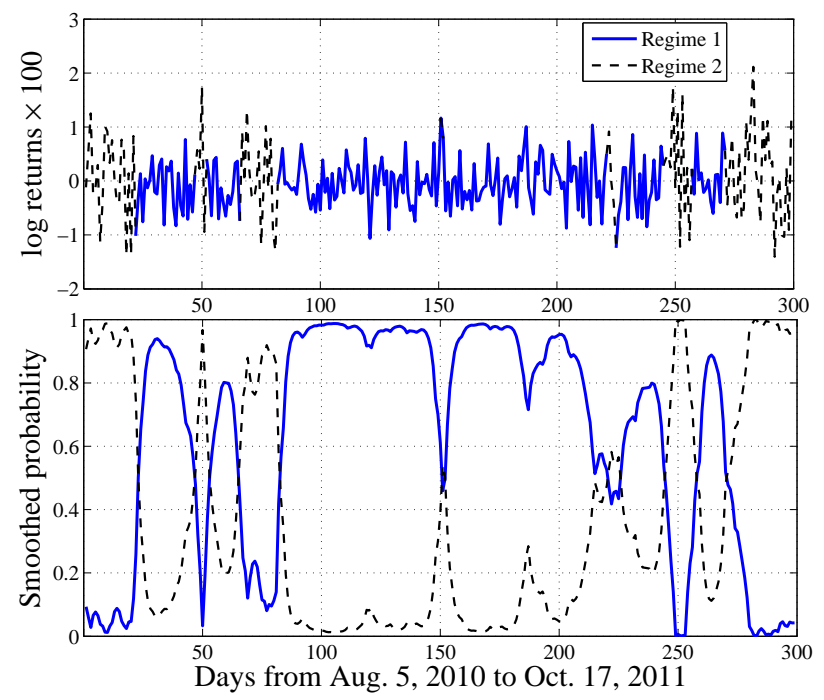

Figure 5.2: Two regimes with smoothed probability for the daily exchange rate in CAD per 100 units of USD 
Table 5.1: Estimated regime parameters for exchange rate in CAD per 100 units of USD

\begin{tabular}{cccc}
\hline Variable & Coefficient & Standard error & $\mathrm{p}$-value \\
\hline$\gamma_{11}$ & 0.96 & 0.06 & 0.00 \\
$\gamma_{22}$ & 0.93 & 0.06 & 0.00 \\
$\mu_{1}$ & -0.0585 & 0.0389 & 0.13 \\
$\mu_{2}$ & 0.0963 & 0.0818 & 0.24 \\
$\sigma_{1}^{2}$ & 0.1904 & 0.0238 & 0.00 \\
$\sigma_{2}^{2}$ & 0.5730 & 0.0792 & 0.00 \\
\hline
\end{tabular}

Table 5.2: Estimated parameters for exchange rate in CAD per 100 units of USD

\begin{tabular}{cccc}
\hline Variable & Coefficient & Standard error & p-value \\
\hline$\mu$ & 0.0018 & 0.0336 & 0.9573 \\
$\sigma$ & 0.5823 & 0.1176 & 0.0000 \\
\hline
\end{tabular}

A simple example with 3 month periods to show the computation is applied. Assume the demand for each term is distributed normally with mean 100 units and standard deviation 5 units. Initial unit price $c_{0}=4 / 0.99=\$ 4.0404$. The holding cost is $\$ 0.8$ per unit per period, which is a constant as explained before. The riskless interest rate is $5 \%$ per year. The gross margin is $\alpha=35 \%$ (Note: Notation $\$$ represents the Canadian dollar). The parameters related to the risk-sharing contract are $\lambda=0.5, \bar{P}=2 c_{0}=8.0808$, and $\underline{P}=0.95 c_{0}=3.8384$. The step size of regime 1 is $\hat{\phi}_{1}=0.02347$ and the step size of regime 2 is $\hat{\phi}_{2}=0.04015$. Then, adjusted step sizes of regimes 1 and 2 are $\widetilde{\phi}_{1}=0.02347$ and $\widetilde{\phi}_{2}=0.04694$, respectively. The branch probabilities of regimes 1 and 2 are:

$$
\begin{array}{lll}
\pi_{\widetilde{\phi}_{1}, u}=0.2340, & \pi_{\widetilde{\phi}_{1}, m}=0, & \pi_{\widetilde{\phi}_{1}, d}=0.7660 \\
\pi_{\widetilde{\phi}_{2}, u}=0.5749, & \pi_{\widetilde{\phi}_{2}, m}=0.2681, & \pi_{\widetilde{\Phi}_{2}, d}=0.1570
\end{array}
$$


Assuming 21 trading days per month (252 trading days in a year), the monthly transition probabilities are : $\gamma_{11}=0.6678, \gamma_{12}=0.3322, \gamma_{21}=0.5813$, and $\gamma_{22}=0.4187$. Unconditional probabilities of regimes 1 and 2 are 0.3637 and 0.6363 , respectively.

We first calculate the unit purchase price on the lattice depicted in Figure 5.3. For example, the step size travelling along the lower branch of the high-volatility regime is $e^{-2 \times 0.02347}$ and unit purchase price at period 2 is $4 / 0.9 * e^{-2 \times 0.02347}=3.8551$. Following this node, the step size travelling along the lower branch of the low-volatility regime is $e^{-0.02347}$ and unit purchase price at period 3 is $3.8551 \times e^{-0.02347}=3.7657$. Since $3.7657<\underline{P}=3.8384$, the actual unit purchase price following the risk-sharing contract is $3.7657+\lambda(\underline{P}-3.7657)=3.8020$.

The value of the contracts for each node are calculated using Figure 5.3, which displays the unit purchase price values. Figure 5.4 shows the expected discounted supply contract's value based on the proposed recursive equations mentioned above. One can find the final discounted supply contract's value by multiplying and then adding these values with unconditional probabilities of the respective regimes. The unconditional probabilities of regimes 1 and 2 are 0.3637 and 0.6363 , respectively. For example, $(0.3637 \times 37.8255)+(0.6363 \times 37.9054)=37.8763$ 


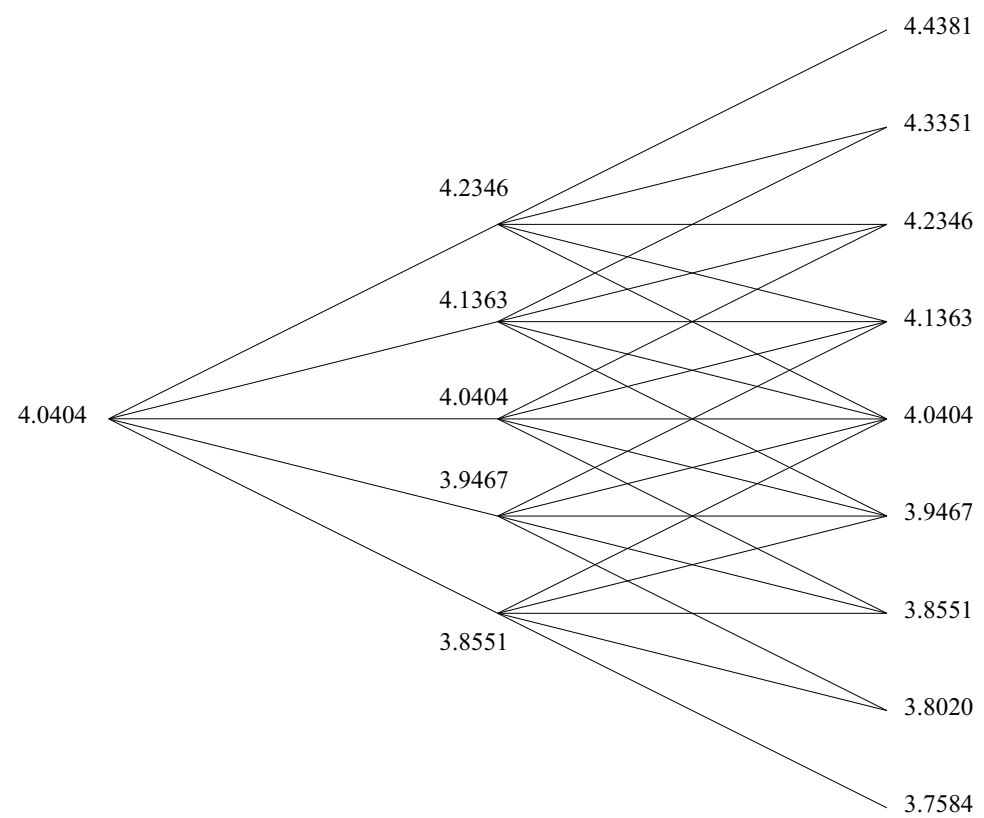

Figure 5.3: Unit purchase prices

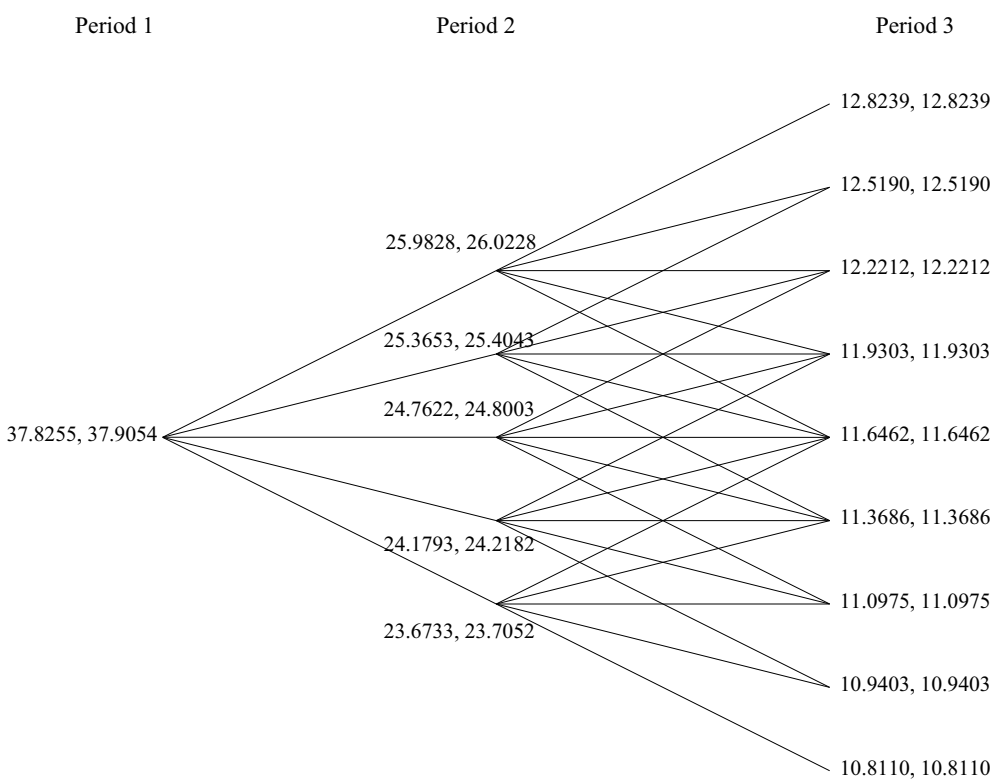

Figure 5.4: Optimal net present values 


\subsection{Sensitivity Analyses}

In this Chapter, a 3-period example is extended to 36-periods (3 years) with the parameter settings presented in the previous section to observe the effects of changes in various problem parameter on the solutions of regime switching and a single Brownian motion models.

\subsubsection{Changes in the gross margin}

Initially, the changes in the profit with different gross margin, $\alpha$, values for the risksharing and without risk-sharing contracts are analysed when exchange rate follows a regime switching and a single Brownian motion. Gross margin, $\alpha$, values are varied between $0.25 \%-0.45 \%$. The results with different gross margins are presented in Figure 5.5 .

From Figure 5.5, as expected when $\alpha$ increases, the expected discounted total profits for all contracts increase. Also, there is no significant profit difference between the contracts. They have almost same profit values.

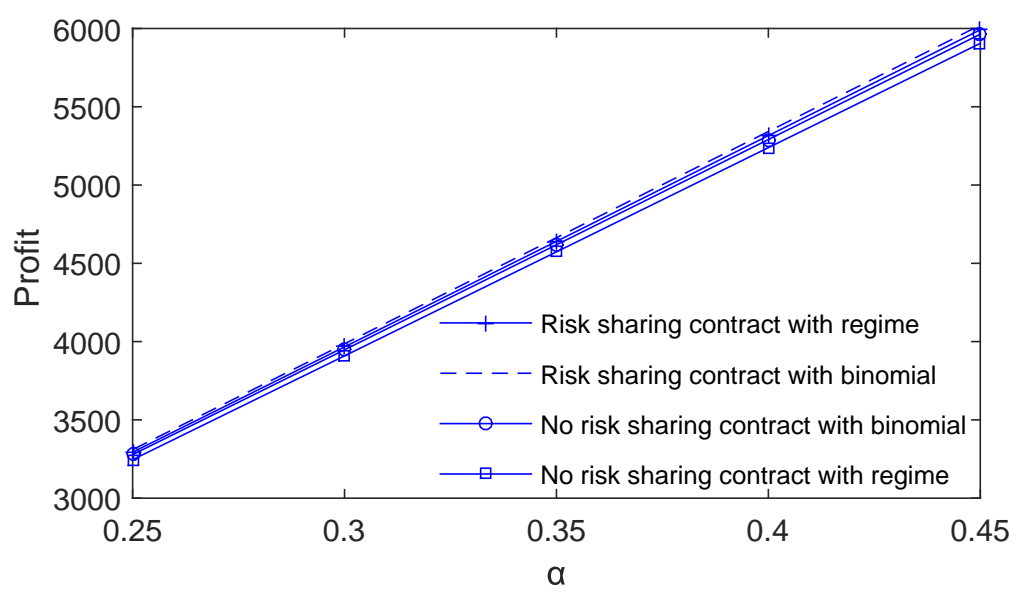

Figure 5.5: Changes in the gross margin 


\subsubsection{Changes in the mean of demand}

In the numerical example, it was assumed that the demand for each period distributed normally with mean of 100 units. In this analysis, the demand per period was assumed to has a normal distribution with varying between 80 and 120 units. Figure 5.6 demonstrates the respective demand changes on the risk-sharing contracts when exchange rate follows a regime switching and a single Brownian motion.

In all instances displayed at Figure 5.6 there is no significant profit variants among the contracts. They have almost same profit values. Moreover, when the demand increases, the expected discounted profit also increases for all contracts because of the revenue rising.

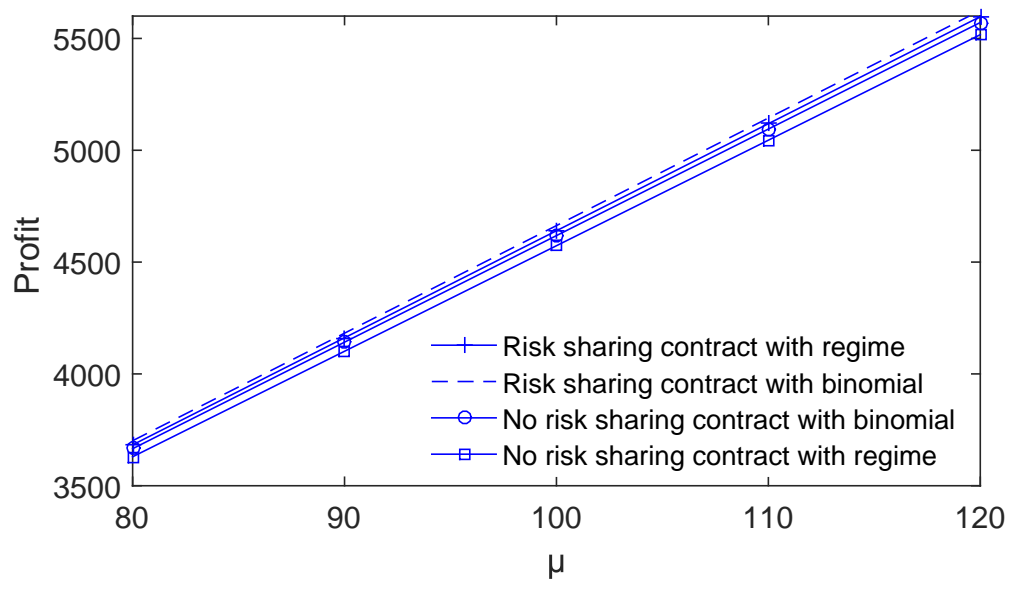

Figure 5.6: Changes in mean of demand

\subsubsection{Changes in the standard deviation of demand}

Next, changes in the profit are examined when there is variations in the standard deviation of the demand . As stated at numerical model, standard deviation of the demand is 5 units. In this analysis, it is varied between 3 and 7 units. Figure 5.7 displays these changes on the risk sharing and no-risk sharing contracts when exchange rate variable 
follows a regime switching and a single Brownian motion.

From Figure 5.7, it can be observed that as standard deviation increases, the expected discounted profit of all contracts decrease. The graph also shows that under the high uncertainty of demand, the profit of the risk-sharing contracts always greater than the no risk-sharing contracts. Therefore, it is especially beneficial to use the risk-sharing supply chain contract when the demand is stochastic.

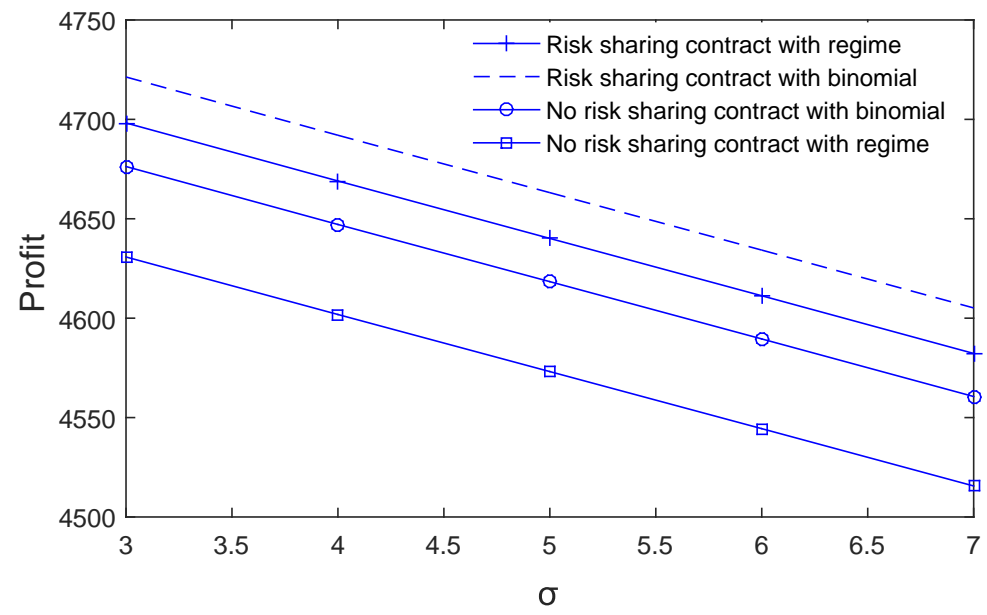

Figure 5.7: Changes in the standard deviation of demand

That observation is also seen in the study of Tibben-Lembke (2004). They proved that base-stock procurement method is optimal for $n$-term problems. They conducted analyses about the impact of variance on profits when the variance rises 20 to 100. It is observed that the overall profit decreases its nearly half value. Also, Hu et al. (2013a) shows that the integrated supply chain's profit suffers from a decrease under demand uncertainty. They indicate that the profit increase becomes more obvious as the demand uncertainty is low. Furthermore, Hu et al. (2013b) also indicates the same outcomes from their studies. 


\subsubsection{Changes in the holding cost}

Next, the changes on the profit with different holding costs for the risk-sharing and without risk-sharing contracts are researched when exchange rate follows a regime switching and a single Brownian motion. Now, holding cost values are varied from $\$ 0.2$ to $\$ 1.4$. Results are presented in Figure 5.8.

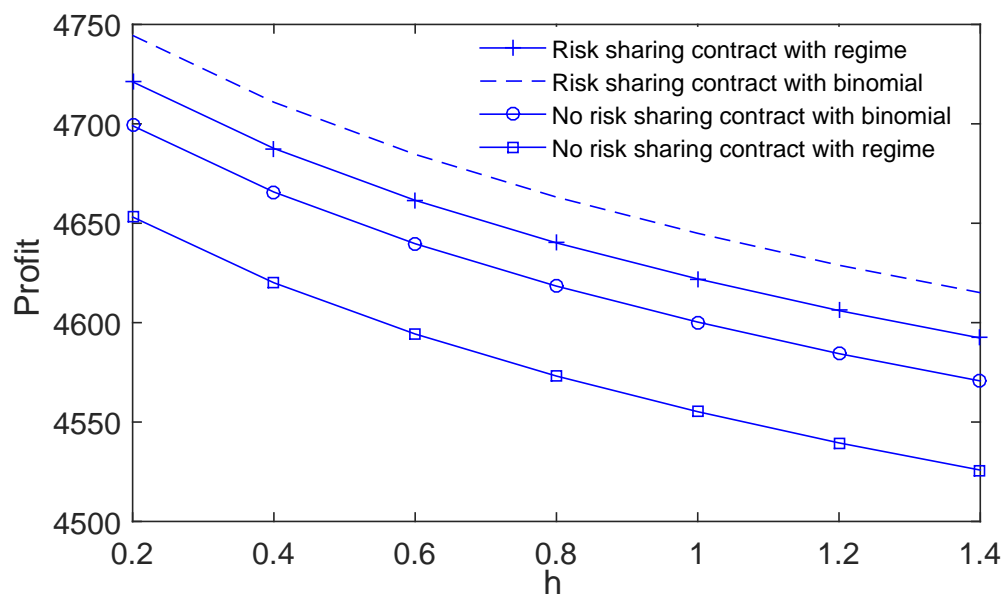

Figure 5.8: Changes in the holding cost

Observe from Figure 5.8 that as holding cost increases, the expected discounted profit for all the contracts are decreased due to the raising of the total costs. However, the return of the both risk-sharing contracts are always superior to the no risk-sharing contracts. This indicates the value of applying the risk-sharing contract. Besides, it can be also noted that the profits of the single Brownian motion (binomial) are always higher than the regime switching processes for all the supply contracts. This is because when the exchange rate follows a single Brownian motion, the profit is overestimated due to not to be able to capture the regime switching behaviour of the variable. And, when the exchange rate follows the regime switching process, the profit is underestimated due to not to be able to capture the binomial behaviour. 


\subsubsection{Changes in the risk-sharing ratio}

Next, analyses are continued with changing the risk-sharing ratio, $\lambda$, when exchange rate follows a regime switching and a single Brownian motion. For this analysis, the risk-sharing ratio is varied between 0 to 1 . Results with varying risk-sharing ratio are presented in Figure 5.9.

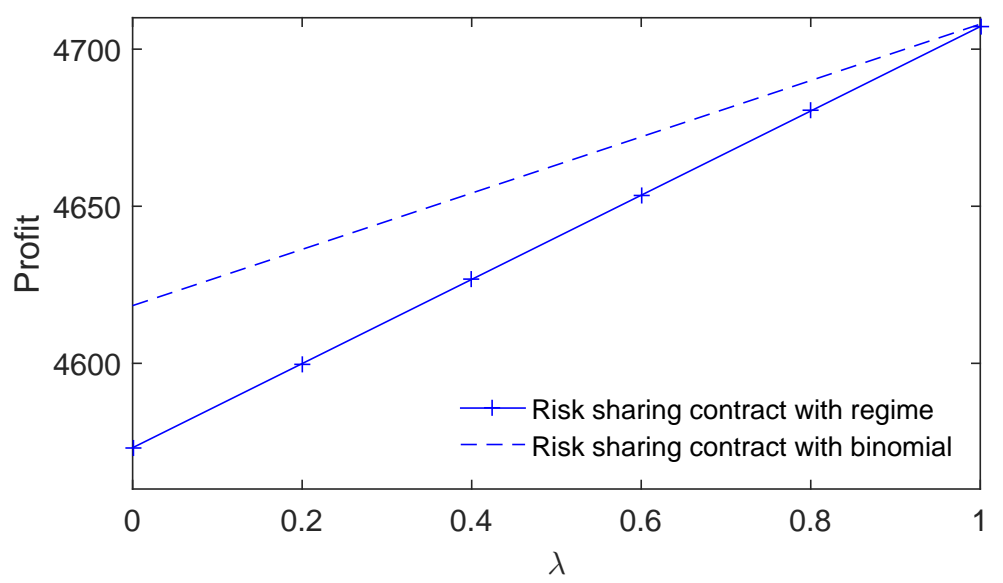

Figure 5.9: Changes in the risk-sharing ratio

As it can be observed from Figure 5.9, for all instances the risk sharing contract in which exchange rate follows a single process have higher profit value than the exchange rate variable fluctuates between different regimes. When $\lambda$ is small, the profit for both contracts are low. If $\lambda$ increases, the profit also rises. This proofs the risk-sharing property has a significant favourable effect on improving profit and worth to use it in the supply chain contracts. Note that according to Equation 2.1, $\lambda=0$ stands for no-risk sharing contract. When $\lambda=1$, again based on Equation 2.1, $P=\bar{P}$ for the unit price above than the upper purchase price limit $(\bar{P})$. And, $P=\underline{P}$ when the unit price under the lower purchase price frontier $(\underline{P})$. Therefore, when $\lambda=1$, both supply contracts have the same profit value as can be seen on Figure 5.9. 


\subsubsection{Changes in the lower price}

Moreover, lower price, $\underline{P}$, diversity is investigated for the risk-sharing contract when exchange rate variable follows a regime switching and a single Brownian motion. For the numerical example, we considers $\underline{P}=0.95 c_{0}=3.8384$. For this analysis, the risksharing contract parameter is altered between 2 and 4 . Results with varying $\underline{P}$ values are displayed in Figure 5.10.

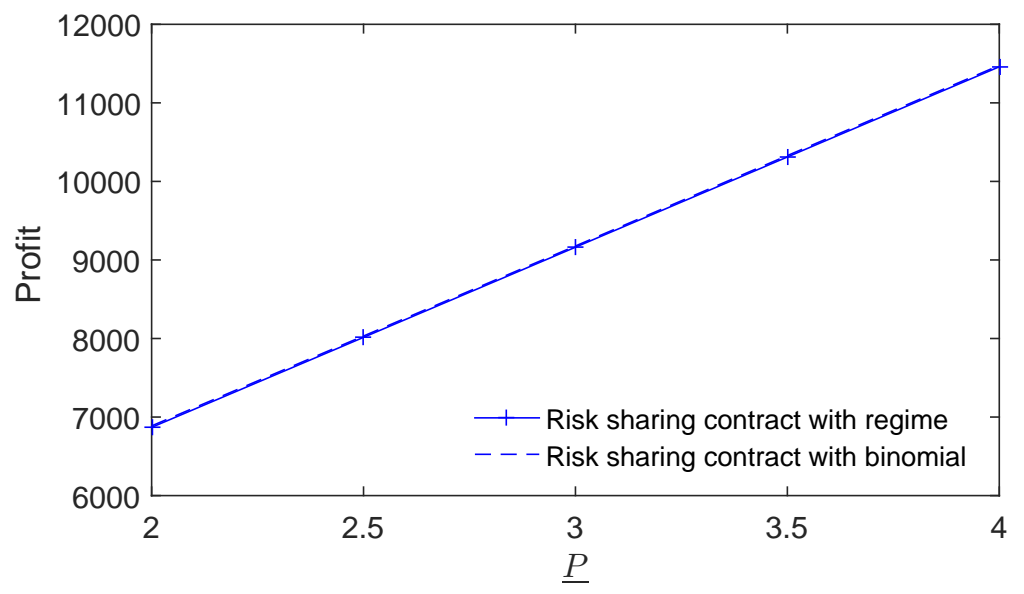

Figure 5.10: Changes in the lower price

As it can be observed from Figure 5.10, the value of the profits are almost same for the risk-sharing contract when exchange rate follows a single process and regime switching process. As $\underline{P}$ increases, profit also increases. The results suggest that the risk-sharing contract may lower the profit as $\underline{P}$ is low, whereas the profit is high as $\underline{P}$ becomes bigger. That is, risk-sharing agreement having a high $\underline{P}$, makes the contract more attractive and moreover increase the compensating opportunity of buyer to the supplier for the lower purchase costs. 


\subsubsection{Changes in the upper price}

Next, an analyse is conducted for changing the upper price $(\bar{P})$ for risk-sharing contract when exchange rate variable follows a regime-switching and a single geometric Brownian motion. For this analysis, risk-sharing contract parameter is varied between 5 and 11 . Results with varying $\bar{P}$ values are demonstrated in Figure 5.11.

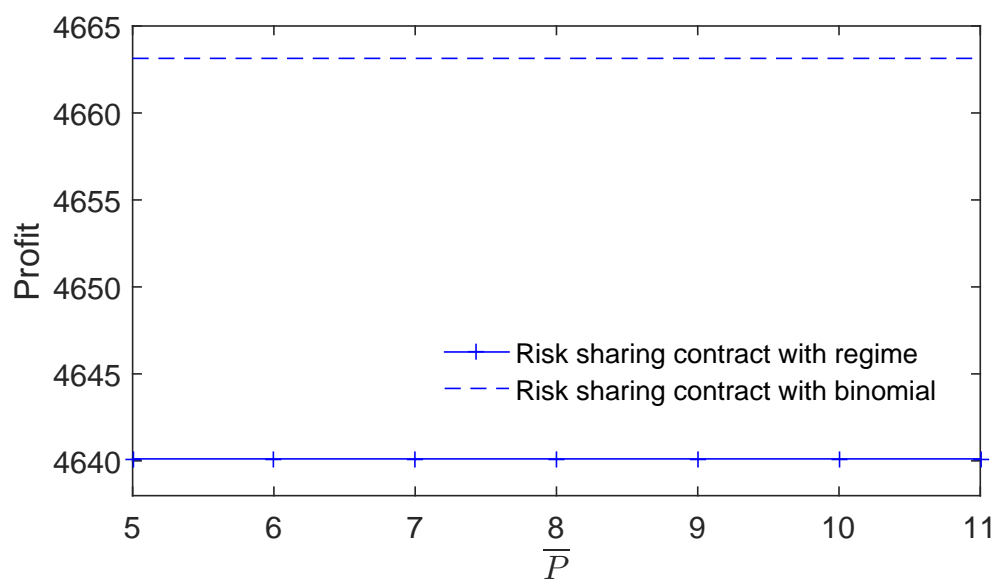

Figure 5.11: Changes in the upper price

From Figure 5.11, profit does not change when the $\bar{P}$ value is increased or decreased . Besides, the profit of the exchange rate for the regime switching process is lower than the single geometric Brownian motion. This is because when the exchange rate follows a single Brownian motion, the profit is overestimated due to not to be able to capture the regime switching behaviour of the variable. And, when the exchange rate follows the regime switching process, the profit is underestimated due to not to be able to capture the binomial behaviour. In that case, we can state that having risk-sharing contract does not give the buyer any significant advantage. 


\subsubsection{Changes in the standard deviations of the exchange rate for regime 1 and regime 2}

Standard deviations $\left(\sigma_{1}, \sigma_{2}\right)$ of the exchange rate are varied from $6 \%-10 \%$ and $10 \%-14 \%$ for regime 1 and regime 2, respectively. Each regime process is still presumed to pursue a geometric Brownian motion. When $\sigma_{1}$ and $\sigma_{2}$ percentages are changed, the step sizes of the lattice and probability of the each branches are modified. Next, the appropriate probability changes are applied to the model and then plotted Figure 5.12 and Figure 5.13. This analyse is conducted for the risk-sharing and no risk-sharing contracts.

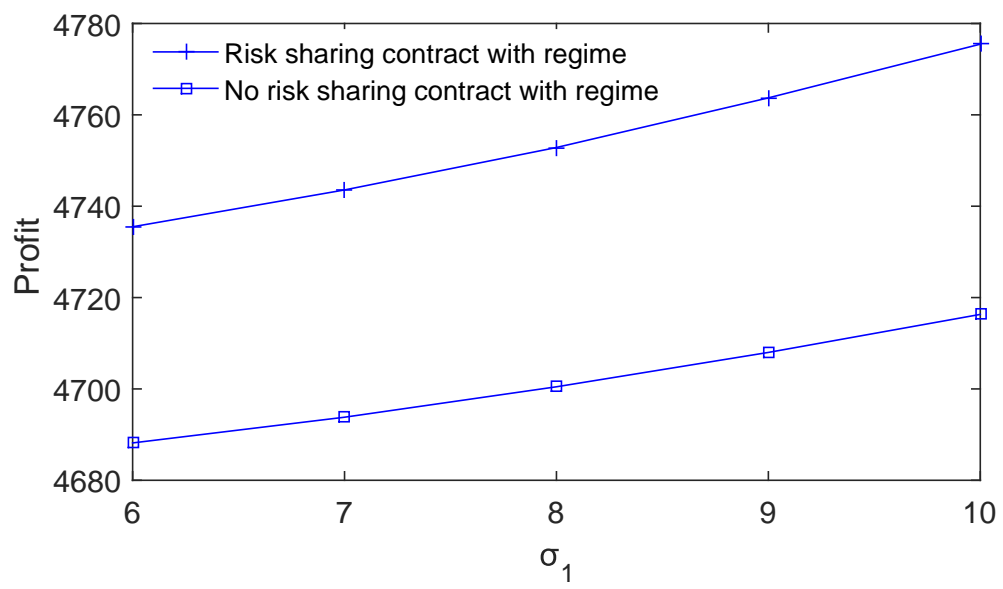

Figure 5.12: Changes of the exchange rate standard deviation for regime 1 


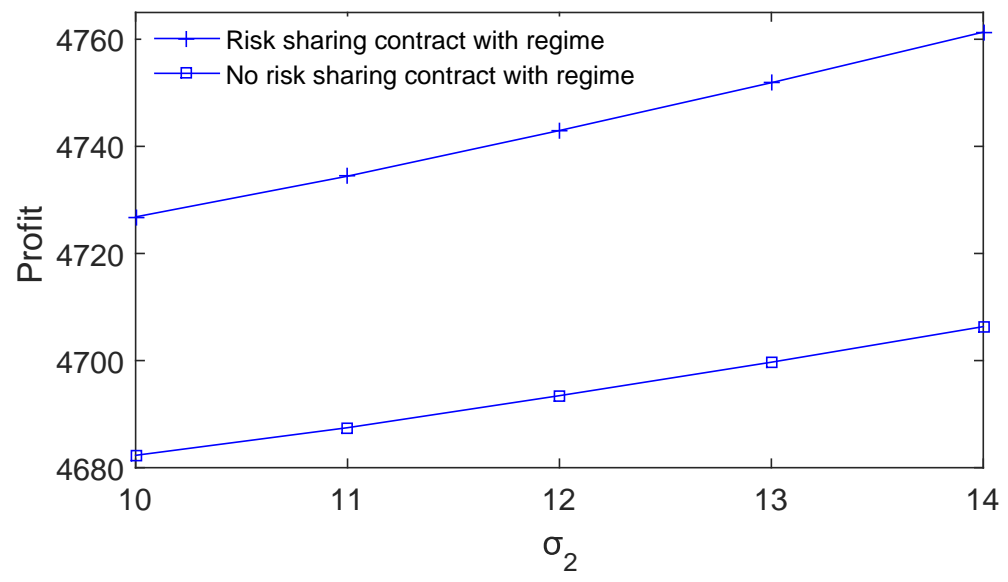

Figure 5.13: Changes of the exchange rate standard deviation for regime 2

From Figure 5.12 and Figure 5.13, it can be observed that as expected when $\sigma_{1}$ and $\sigma_{2}$ increase, profit also increases. This outcome obviously shows that when the uncertainty of the exchange rate is high and volatile, it is definitely more beneficial to use the risk-sharing supply chain contract with the perspective of expected discounted profit value. Furthermore, according to the risk (standard deviation) and return (profit) trade off relationship as the risk increases, the profit also increases. So, the results of this sensitivity analyse exactly show and proof that property.

\subsubsection{Changes of the exchange rate standard deviation for the single trend process}

Lastly, standard deviation, $\sigma$, for an exchange rate is varied between $5 \%$ and $13 \%$ when the underlying variable follows a single process which is geometric Brownian motion. When the standard deviation percentages are changed, the step size of the lattice and probabilities of the each branches are also altered. Next, the appropriate probability modifications are applied to the model and then plotted Figure 5.14. 


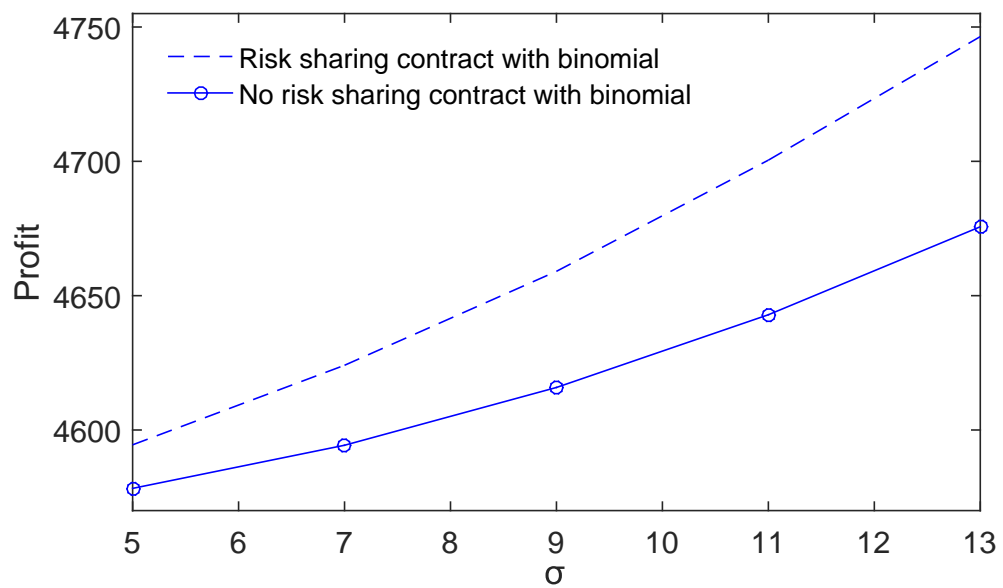

Figure 5.14: Changes of the exchange rate standard deviation for a single regime model

Figure 5.14 demonstrates the profit changes for the risk-sharing and without risksharing agreements. This analyse showed that as $\sigma$ goes up, profit also goes up. One may also conclude that when $\sigma$ is low, the difference between the profit values of the risk-sharing and without risk-sharing contracts is small and considerably close to the each other. However, when $\sigma$ is high, the difference between the expected discounted profit values are also high. Moreover, the profit value of the risk-sharing contract is greater than the without risk-sharing supply contract. This results indicate that, risksharing contract is more profitable under the high and volatile uncertainty conditions of the exchange rates. 


\section{Chapter 6}

\section{Conclusion}

In this project, a new modelling framework is proposed for a supply contract decision problem. The problem is motivated by the procurement decision issue of a Canadian buyer sourcing from USA. It is thought that the buyer encounters with a random demand and also random price due to the exchange rate volatility between Canadian and US dollar. Therefore, a risk-sharing supply contract is suggested for the price uncertainties to compensate the supplier when the price decreases. And also, helps the buyer when the currency appreciate. Unlike the existing literature, demand for the Canadian buyer and purchasing price are considered to be stochastic and modelled as a geometric Brownian motion. Exchange rate for product price assumed to be followed a regime-shifting process for $n$-regimes. Each trend is defined with a geometric Brownian motion.

Problem is modelled by using a multi-period setting. $n$-period lattice model is developed for the valuation of the risk-sharing contract. We generated a dynamic modelling method for the solution of the multi-period lattice model. In the supply contract literature, $n$-period lattice valuation and regime switching model have never been used before for the flexible risk sharing agreements under price uncertainty.

A numerical example of the model is presented with the real data for 3 month periods when the demand variable follows a single regime and price exchange rate follows two 
regimes. A lattice approach is presented to value the unit purchase price and risk-sharing contract. Furthermore, several extensive sensitivity analyses are studied for 36 month periods to observe the effect of changes in various problem parameters on the long run for risk-sharing and no risk-sharing contracts when exchange rate follows a single and two regimes.

It is observed that as standard deviations of demand are increased, the expected discounted profit value of all contracts decreased. Also, it is seen that under the high uncertainty of demand, the profit of the risk-sharing contracts always greater than the no risk-sharing contracts. Therefore, it is especially beneficial to use the risk-sharing supply contract when the demand is stochastic. Also, it is displayed for all the sensitivity analyses that the return of the risk-sharing contracts are always superior to the no risksharing agreements. Besides, note that profits of the single Brownian motion are always higher than the regime switching processes for all the supply contracts. This is because when the exchange rate follows single Brownian motion, the profit is overestimated due to not to be able to capture the regime switching behaviour of the variable. And, when the exchange rate follows the regime switching process, and also the profit is underestimated due to not to be able to capture the binomial behaviour.

Furthermore, the risk sharing ratio is changed. It is observed that the profit for both the regime switching and binomial supply contract is high, as risk sharing ratio is high. This proofs risk-sharing property has a significant favourable effect on profit improvement and worth to use it in the supply contracts. Besides, the standard deviations of the exchange rates are varied for regime switching and single Brownian motion processes. The results displayed that as risk are increased, the profit value also increased and the profit value of the risk-sharing contract is greater than the no risk-sharing supply contract. These outcomes show that when the uncertainty of the exchange rate is high and volatile, it is definitely more beneficial to use the risk-sharing contract.

The proposed lattice approach can be implemented to value financial and real options 
as a variable pursues a regime-switching process owns more than two regimes. This project can be extended for the future studies. For instance, it is possible to modify the demand process as an $n$-regime model. Another possible future research direction is to consider an incentive factor to be offered in order to stimulate the procurement of the buyer from the supplier. In contrast with the incentive factor, the buyer can impose a penalty cost when the delivery quantity is below the ordered level. And then, the supplier pays a penalty for an amount of below the order. The related mathematical model of this problem can be developed as dual optimization for both buyer and supplier. In addition to incentive and penalty analyses, the project can be broaden for more than two supplier sourcing commitments within a multi-period setting through a discrete and finite planning horizon. 


\section{Bibliography}

Albeniz, V. M. and Simchi-Levi, D. (2015). A portfolio approach to procurement contracts. Production and Operations Management, 14:90114.

Bassok, Y. and Anupindi, R. (1997). Analysis of supply contracts with total minimum commitment. IIE Transactions, 29:373381.

Bergman, U. and Hansson, J. (2005). Real exchange rates and switching regimes. Journal of International Money and Finance, 24:121-38.

Black, F. and Scholes, M. (1973). The pricing of options and corporate liabilities. Journal of Political Economy, 81:637-659.

Bollen, N. (1998). Valuing option in regime-switching models. Journal of Derivatives, 6:38-49.

Bollen, N. (1999). Real options and product life cycles. Management Science, 45:670-684.

Bollen, N., Gray, S., and Whaley, R. (2000). Regime-switching in foreign exchange rates: Evidence from currency option prices. Journal of Econometrics, 94:239276.

Cheung, Y. W. and Erlandsson, U. G. (2005). Exchange rates and markov switching dynamics. Journal of Business and Economic Statistics, 23:314320.

Engel, C. and Hamilton, J. (1990). Long swings in the dollar: Are they in the data and do markets know it? American Economic Review, 80:689-713. 
Feng, B., Yao, T., and Jiang, B. (2013). Analysis of the market-based adjustable outsourcing contract under uncertainties. Production and Operations Management, 22:178-188.

Fotopoulos, S., Hu, X., and Munson, C. (2008). Flexible supply contracts under price uncertainty. European Journal of Operations Research, 191:253-263.

Gavirneni, S. (2004). Periodic review inventory control with fluctuating purchasing costs. Operations Research Letters, 32:374-379.

Goutte, S. and Zou, B. (2011). Foreign exchange rates under markov regime switching model. Crea discussion paper series, Center for Research in Economic Analysis, University of Luxembourg.

Guglielmo, C. and Hesseldahl, A. (2010, April 19). Apple may have ipad shortages amid production issues. Bloomberg Businessweek.

Gurnani, H. and Tang, C. (1999). Optimal ordering decisions with uncertain cost and demand forecast updating. Management Science, 45:1456-1462.

Haksoz, C. and Seshadri, S. (2007). Supply chain operations in the presence of spot market: A review with discussion. Journal of the Operational Research Society, $58: 14121429$.

Hochbaum, D. S. and Wagner, M. R. (2015). Range contracts: Risk sharing and beyond. European Journal of Operational Research, 243:956-963.

Hu, F., Lim, C.-C., and Lu, Z. (2013a). Coordination of supply chains with a flexible ordering policy under yield and demand uncertainty. International Journal of Production Economics, 146:686693.

Hu, F., Lim, C. C., Lu, Z., and Sun, X. C. (2013b). Coordination in a single-retailer two-supplier supply chain under random demand and random supply with disruption. Discrete Dynamics in Nature and Society, pages 1-12. 
Kamrad, B. and Siddique, A. (2004). Supply contracts, profit sharing, switching, and reaction options. Management Science, 50:64-82.

Lee, H. and Chen, S. (2006). Why use markov-switching models in exchange rate prediction. Economic Modelling, 23:6628.

Li, C.-L. and Kouvelis, P. (1999). Flexible and risk-sharing supply contracts under price uncertainty. Management Science, 45:1378-1398.

Li, S., Murat, A., and Huang, W. (2009). Selection of contract suppliers under price and demand uncertainty in a dynamic market. European Journal of Operational Research, 198:830847.

Lo, M. C. and Morley, J. (2015). Bayesian analysis of nonlinear exchange rate dynamics and the purchasing power parity persistence puzzle. Journal of International Money and Finance, 51:285-302.

Marin, V. H., Delgado, L. E., Vila, I., Tironi, A., Barrera, V., and C.Ibanez (2014). Regime shifts of cruces river wetland ecosystem: current conditions, future uncertainties. Lat. Am. J. Aquat. Res., 42.

Munson, C. L., Fotopoulos, S. B., and Hu, X. (2012). Purchasing decisions under stochastic prices: Approximate solutions for order time, order quantity and supplier selection. Annals of Operations Research, 201:287-305.

Nembhard, H., Shi, L., and Aktan, M. (2005). A real-options-based analysis for supply chain decisions. IIE Transactions, 37:945-56.

Sethi, S., Yan, H., and Zhang, H. (2004). Quantity flexibility contracts: Optimal decisions with information updates. Decision Sciences, 35:691-712.

Tibben-Lembke, R. S. (2004). N-period contracts with ordering constraints and total 
minimum commitments: Optimal and heuristic solutions. European Journal of Operational Research, 156:353-374.

Wahab, M. and Lee, C. (2009). Pricing swing options with regime switching. Annals of Operations Research, 185:139-160.

Yuan, C. (2011). Forecasting exchange rates: The multi-state markov-switching model with smoothing. International Review of Economics and Finance, 20:342362. 